\title{
Toxoplasma gondii: 1908-2008, homage to Nicolle, Manceaux and Splendore
}

\author{
David J P Ferguson \\ Nuffield Department of Clinical Laboratory Science, Oxford University, John Radcliffe Hospital, OX3 9DU, Oxford, UK
}

\begin{abstract}
The discovery of Toxoplasma gondii independently by Nicolle and Manceaux (1908) and Splendore (1908) was to open a "Pandora's Box" that has led research on this parasite into a number of scientific disciplines. In the 100 years since its discovery, the mystery surrounding T. gondii and its inter-relationship with humans has continued to provide a stimulating source of material in many areas of research, resulting in the publication of almost 20,000 papers and a number of books. This flood of diverse information shows no sign of abating, with an average of 10 papers per week appearing in PubMed. Herein, it is impossible to do more than provide a very superficial comment on what has become a massive body of scientific information. T. gondii has many unique features and seems to be the "exception to almost every rule" thus acting as a focus for research in disciplines from epidemiology to immunology to human behaviour to cell biology to human disease. In this review a number of the historical advances will be mentioned and combined with a description of the basic biology of the parasite.
\end{abstract}

Key words: Toxoplasma gondii - toxoplasmosis - history - life cycle - developmental stages

\section{History}

It is said that history is written by the survivors and therefore has personal bias. For this reason, it is easier to write about developments that occurred before becoming personally involved in research on Toxoplasma; in my case, developments prior to 1970 . It is difficult to be totally detached when reviewing the history of Toxoplasma since 1970. I am biased by my personal experiences of nearly 40 years in the field. Therefore this article should not be considered in anyway as a definitive work. It covers the points I feel have had a long-term impact on Toxoplasma research. The interest in Toxoplasma is ongoing and has recently been the subject of two major textbooks (Ajioka \& Soldati 2007, Weiss \& Kim 2007). These books provide wide ranging and upto-date collections of reference works on many aspects of Toxoplasma research and will be essential reading for anybody entering the field of Toxoplasma research.

The starting point is, of course, the identification of the parasite in the North African rodent, the gundi, by Nicolle and Manceaux (1908) and a rabbit in Brazil by Splendore (1908). The involvement of these authors has been covered in the introduction to the centenary meeting. The name Toxoplasma gondii was proposed by Nicolle and Manceaux (1909) based on the shape of the infectious stage (mod. L toxon: arc or bow, plasma: life; gondii may have resulted from a misspelling of the original host, the gundi - Ctenodactylus gundi) (Fig. 1A). Both groups thought the parasite was related to Leishmania.

Copyright of all micrographs is retained by DJP Ferguson.

Supported by an equipment grant from the Wellcome Trust.

Corresponding author: david.ferguson@ndcls.ox.ac.uk

Received 10 October 2008

Accepted 20 October 2008
Little could it have been realised at the time, that this relatively non-descript parasite, only observed in laboratory animals, could turn out to be such an important pathogen of both humans and their domestic animals.

Between 1908-1937 there were a number of reports identifying Toxoplasma-like organisms in a number of animal species, including humans. However, the first detailed scientific study was undertaken using techniques previously employed in studies of viruses (Sabin \& Olitsky 1937). They showed that Toxoplasma was an obligate intracellular parasite that could be passaged in laboratory animals by intracranial, subcutaneous and intraperitoneal inoculation of brain homogenates. In addition, variations in virulence between isolates and increased virulence after continuous passage were noted. They also showed that serum from monkeys recovering from T. gondii contained "neutralizing" or "protective" antibodies. Interestingly, they also noted that mice, fed on recently dead, infected animals, became infected. They suggested as early as 1937 that "one method of natural dissemination may be by means of eating of Toxoplasma-contaminated tissue" (Sabin \& Olitsky 1937). At this time, a human infection with Toxoplasma was noted in a three day old infant suffering from encephalomyelitis (Wolf \& Cowen 1937). Abner Wolf and colleagues identified, at autopsy, parasites in the brain associated with necrotic and granulomatos lesions and showed that the parasite could be transferred to mice, rabbits and rats by intracranial inoculation of brain tissue from the child (Wolf et al. 1939, 1940). A review of additional cases showed that these represented examples of congenital transmission. Although the mothers were asymptomatic, they did have antibodies (Wolf et al. 1941). This showed Toxoplasma to be a human pathogen capable of and associated with congenital transmission. Around this time, a fatal case of toxoplasmosis in an adult was also identified (Pinkerton \& Weinman 1940, Sabin 
1942). In the late 1940s and early 1950s Toxoplasma was shown to be involved in inflammatory diseases of the eye (Wilder 1952, Frenkel \& Jacobs 1958). This led to the proposal that many cases of adult retinochoroiditis are due to $T$. gondii (Feldman 1953). In the early 1950s, a form of glandular toxoplasmosis was also described (Siim 1955) in which the lymph nodes exhibited characteristic pathological changes. Interestingly, few parasites were normally associated with these lesions. These combined studies confirmed Toxoplasma as a rare cause of debilitating, even life threatening, disease in humans.

In 1948, a serological technique was developed to identify humans/animals infected with the parasite by characterising antibodies directed against Toxoplasma (Sabin \& Feldman 1948). The Sabin and Feldman dye test was based on identifying specific Toxoplasma antibodies in patient serum that altered the staining characteristic of tachyzoites and thus, through titration, allowed the level of specific antibody to be quantified (antibody titer). It

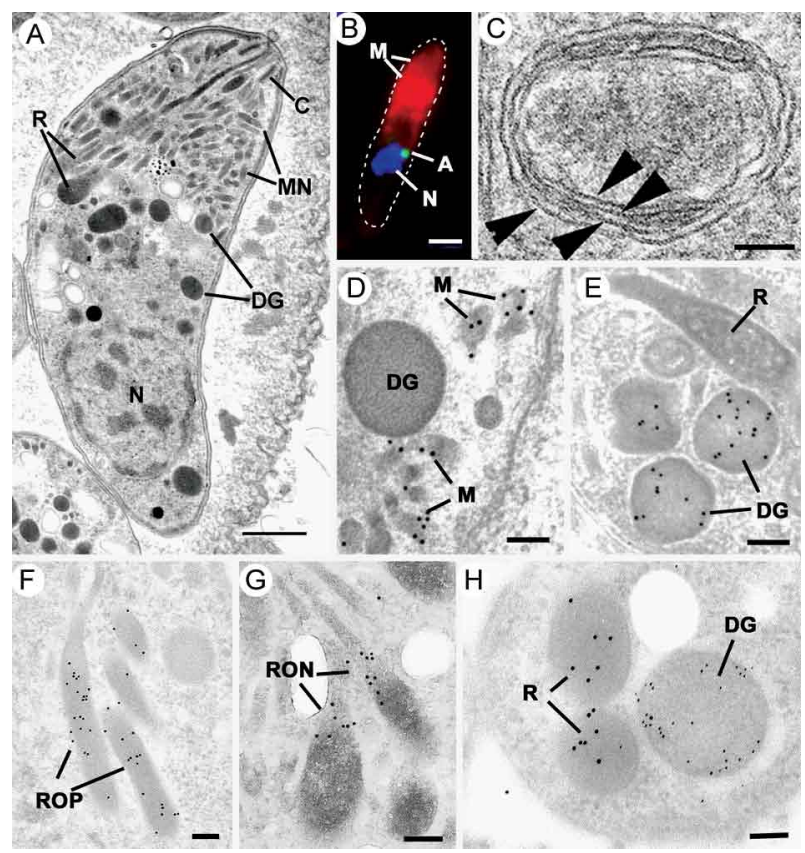

Fig. 1A: electron micrograph of a longitudinal section through an infectious stage (bradyzoite) showing the characteristic apical organelles of conoid (C), rhoptries (R), micronemes $(\mathrm{MN})$ and dense granules $(\mathrm{DG})$ and the posteriorly located nucleus $(\mathrm{N})$. Bar $=500 \mathrm{~nm}$; B: immuno-fluorescent image of a merozoite double labelled with anti-MIC 4 (red) and anti-enoyl reductase (green), showing the diffuse anterior staining of the micronemes (M) (red) and the single perinuclear apicoplast (A) (green) containing enyl reductase. N: nucleus. Bar $=1 \mu \mathrm{m} ; \mathrm{C}$ : detail of an apicoplast showing the four limiting membranes (arrowheads). Bar $=100 \mathrm{~nm}$; D-H: immuno-stained electron micrographs with the location of various antibodies identified using gold particles. Bars $=100 \mathrm{~nm}$; D: Section stained with anti-MIC4 showing it located within the micronemes (M). DG: dense granule; F, G: sections showing ROP proteins (F) associated with the body and RON proteins $(\mathrm{G})$ associated with the neck of the rhoptries; H: cross sectioned merozoite double labelled with anti-ROP (10 nm gold) and anti-GRA (5 $\mathrm{nm}$ gold) allowing the rhoptries $(\mathrm{R})$ to be distinguished from the dense granule $(\mathrm{G})$. became the gold standard that all other serological tests are judged against. This test made it possible to carry out large scale studies to identify individuals (both humans and animals), who had been infected with the parasite. The finding of a high proportion of the human and domestic animal population carrying antibodies to Toxoplasma was a major surprise and changed the perception of infection with the parasite as being relatively rare (few cases identified due to clinical disease) into one of the most common parasites infecting humans and domestic animals. It changed from being considered a rare exotic infection into one of our more common human parasitic infections, fortunately with the majority of infections being self limiting with mild symptoms or asymptomatic. The Sabin Feldman Dye Test has been the basis for the large number of epidemiological studies and identified the parasite as a single species, with the ability to infect all warm-blooded animals (both birds and mammals) and with a world-wide distribution (Tenter et al. 2000).

In the 1950s, the question was being asked: "How are large numbers of humans and animals becoming infected with $T$. gondii?" It was known that congenital infection could occur but the mechanism whereby adults were infected was, as yet, unknown. Due to the early observation of the tachyzoites of Toxoplasma within macrophages and circulating in the blood it was thought that the parasite might be related to Leishmania. Consequently, numerous studies were undertaken to try and show an insect vector but these proved totally fruitless. Based on the parasite stages known at that time (tachyzoite and tissue cyst) (Lainson 1958), it was first suggested that carnivorism could be a possible mechanism of infection (Weinman \& Chandler 1954). In 1960 it was shown that bradyzoites in tissue cysts could survive exposure to acid and trypsin confirming the possible role of ingestion of tissue cyst in parasite transmission (Jacobs et al. 1960). The role played by eating undercooked or uncooked meat in transmission of Toxoplasma to humans was confirmed by Desmonts et al. (1965). In a tuberculosis hospital in Paris where raw meat was given for therapeutic purposes it was observed that the annual acquisition of Toxoplasma antibodies rose from $10 \%$ per annum prior to admission to $50 \%$ annually when barely seared meat was given. When the beef and horse meat were substituted with lamb chops, the acquisition rate rose to $100 \%$ per annum (Desmonts et al. 1965).

However, the observation that Toxoplasma could be transmitted through carnivorism could not explain the high incidence in herbivores or strict vegetarians (Jacobs 1963). Until the mid 1960s, this was a complete mystery. However, the first clue of a possible alternative mechanism was the finding that some form of the parasite could be isolated from cat faeces that could transmit the infection orally to mice and which could survive for over a year in water (Hutchison 1965). Since neither the tachyzoite nor bradyzoite could survive this treatment, the search was then on for this new form of Toxoplasma. Initially it was proposed that the parasite might be protected within the ovum of the cat nematode, Toxocara cati, which also infected the original cats (Hutchison 1967); a not unreasonable hypothesis since the flagel- 
late Histomonas was known to be transmitted via the Heterakis eggs. However intensive work by groups in the USA and UK showed that the infectious agent could be separated from Toxocara ova and was also present in faeces from Toxocara negative cats (Jacobs 1967, Dubey 1968, Hutchison et al. 1968, Frenkel et al. 1969, Sheffield \& Melton 1969). In the samples lacking Toxocara ova, a number of typical coccidian oocysts were identified, which were initially described as the "new cyst" of T. gondii (Work \& Hutchison 1969) (Fig. 2). The final definitive proof was produced almost simultaneously by groups in the USA, UK, Germany and Holland, resulting in the identification of the resistant form of Toxoplasma as a coccidian oocyst with typical coccidian asexual and sexual development occurring in the small intestine of the cat (Fig. 3) (Hutchison et al. 1969, 1971, Frenkel et al. 1970, Overdulve 1970, Sheffield \& Melton 1970, Witte $\&$ Piekarski 1970). Finally the complete life cycle of $T$. gondii had been characterized defining Toxoplasma as a coccidian parasite with the cat as the definitive host and any warm-blooded animal being able to act as the intermediate host (Fig. 4). The infectious forms in faeces were protected in the external environment within a resistant oocyst wall. The oocysts of Toxoplasma are unsporulated when released in the faeces but sporulate to form an Isospora-like oocyst with two sporocysts each containing four sporozoites (Dubey et al. 1970) (Fig. 2). Today the coccidian nature is so ingrained in our thinking that it is difficult to appreciate how revolutionary this concept was prior to 1970 . It is of interest that similar oocysts were identified in the original samples examined by Hutchison (1965), but the idea that Toxoplasma could be a coccidian parasite was unthinkable at that time so these were discarded as possible contaminants, although, in retrospect, they probably were Toxoplasma oocysts.
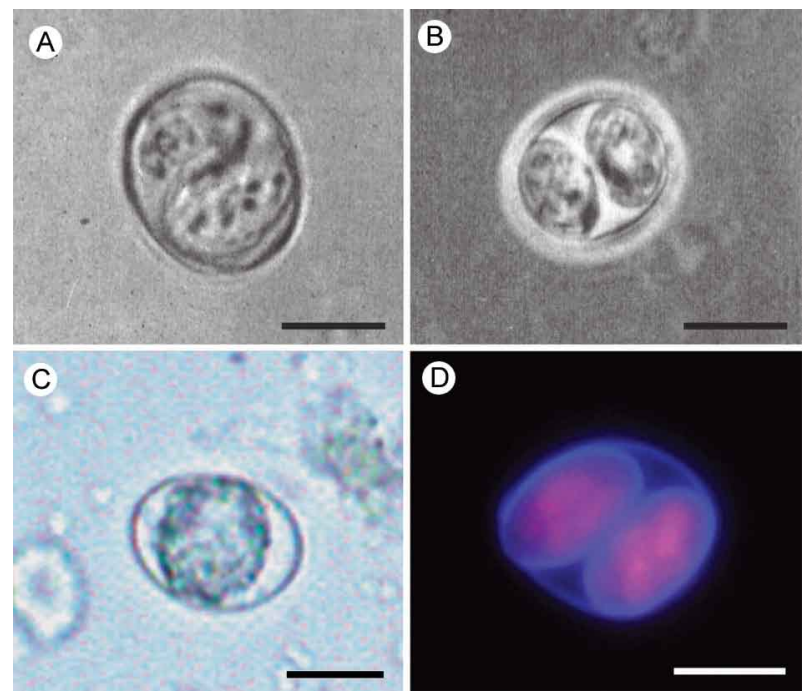

Fig: 2A, B: copies of the original micrographs showing the structure of the "new cyst" (oocyst) of Toxoplasma gondii (Work \& Hutchison 1969); C: light micrograph of an unsporulated oocyst showing the single cytoplasmic mass; D: fluorescent image of a sporulated oocyst with two sporocysts showing the auto-fluorescence of the oocyst and sporocyst wall. Bars $=5 \mu \mathrm{m}$.
Therefore, approximately 60 years after its discovery, the complete life cycle of $T$. gondii was finally elucidated. Now it was possible to explain the widespread infection in all warm blooded animals (both carnivores and herbivores) including humans. Infections can result in one of three ways (Fig. 4). The first, and rarest way, is congenital transmission. It occurs if a female (human or animal) becomes infected for the first time during pregnancy with the circulating tachyzoites associated with the acute phase crossing the placenta to infect the fetus. However, for the more common acquired infection, it was now possible to identify two mechanisms both involving the oral route but employing different parasite stages. The first was carnivorism involving the ingestion of tissue cysts in tissue from chronically infected intermediate hosts and would explain the high incidence in carnivores. The second was from the ingestion of sporulated oocysts resulting from the contamination of food or water with cat faeces and would explain the incidence in herbivores. However, in omnivores such as humans both mechanisms could play a role and the relative importance of each is the subject of much discussion. In humans, it is likely that the lifestyle of the individual plays an important role in how the parasite is transmitted. In populations that eat raw or under cooked meat, the ingestion of tissue cysts is likely to be an important source of infection, while, in strict vegetarians, ingestion of oocysts would be more likely. However, for the majority of the human population, transmission could occur by either mechanism.

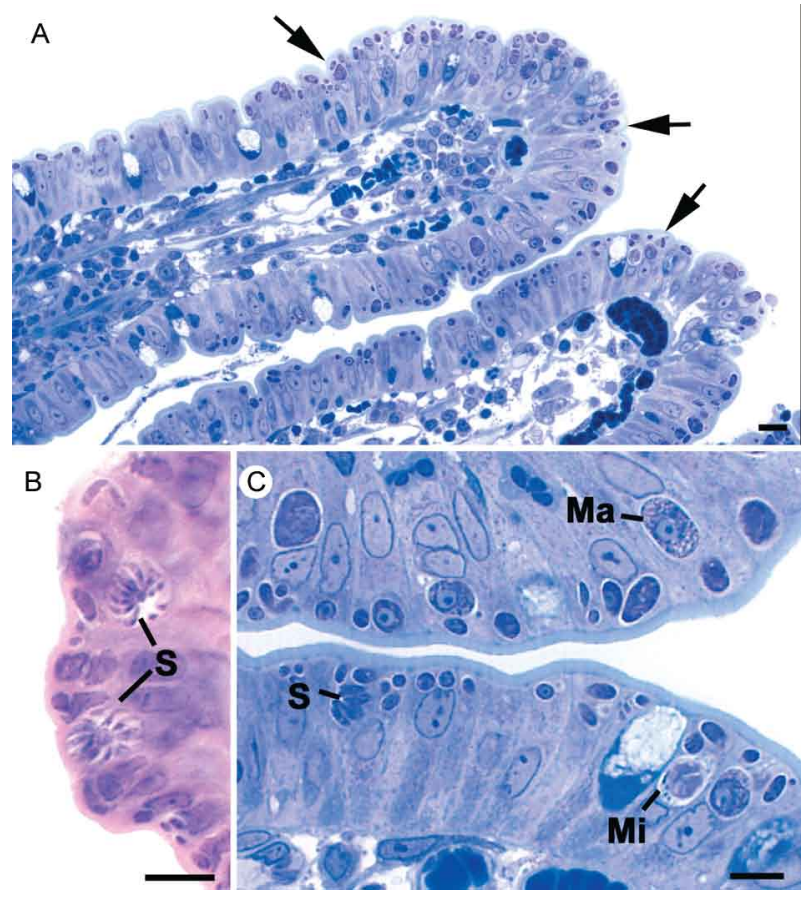

Fig. 3A-C: light micrographs through the small intestine of the cat showing the appearance of the various coccidian stages (both asexual and sexual) developing in the enterocytes (arrows). Ma: macrogametocyte; Mi: microgametocyte; S: schizont. Bars $=10 \mu \mathrm{m}$. 


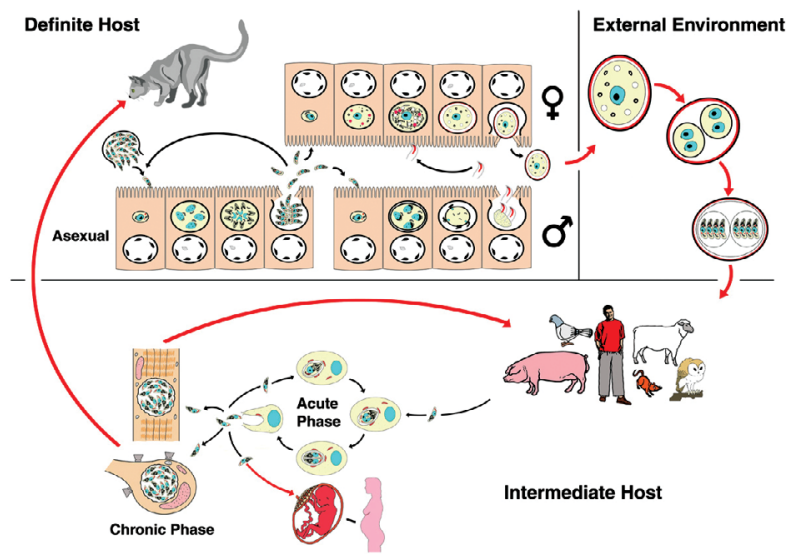

Fig. 4: diagram summarising the complete life cycle of Toxoplasma gondii (Ferguson 2002, with permission).

Until 1970, all the known coccidian parasites had a life cycle that involved a simple oral/faecal/oral infection and transmission cycle. Why had Toxoplasma evolved this elaborate life cycle involving an intermediate host? It is likely that environmental contamination is a reasonably efficient mechanism for transmission between ground feeding animals such as herbivores or omnivores with oocyst ingestion occurring while feeding. However, faecal contamination is likely to be less efficient in nonground feeding animals such as carnivores. Therefore, it is not too surprising that certain coccidian parasites of carnivores have adapted their life cycle to ameliorate this problem. Subsequent to the discovery of the life cycle of Toxoplasma, a sub-group of the Coccidia, known as the "cyst forming Coccidia" (Besnoitia, Sarcocystis and Frenkelia), were also shown to be coccidian parasites of carnivores that have evolved the ability to infect intermediate hosts, normally a herbivore that is a food source for the definite carnivorous host. In the majority of cases, the parasites maintain a narrow range of both definitive and intermediate hosts (Dubey 1977). Here again, Toxoplasma "bucks the trend" in the fact that it is totally indiscriminate in its choice of intermediate host, with any warm-blooded animal (bird or mammal), including humans, able to act as an intermediate host. This indiscriminate blunderbuss approach by Toxoplas$m a$ may be inherently inefficient in that the majority of intermediate hosts will never be eaten by a definitive host. However, it will be efficient in ensuring that any intermediate host that is eaten is more likely to be infected. Therefore the parasite can live with the massive wastage associated with this process. This is the situation in humans, where a third of the world population that is infected with Toxoplasma represents a total loss to the parasite, since modern human cultural behaviour results in death of the parasite with host - we are rarely the source of a meal for feline carnivores!

These oocysts are remarkable structures and I have been horrified to hear of young researchers working with this stage in open laboratories. This stage should be treated with extreme caution within proper containment facilities. We all know that standard laboratory practice will prevent laboratory infection due to the sensitivity of the tachyzoites and tissue cysts to normal laboratory disinfectants. However, it cannot be overemphasized that the oocyst is a totally different proposition. This stage is resistant to all normal laboratory disinfectants. This is due to the oocyst wall, which provides both structural strength and resistance to chemical insult, although they are sensitive to heat and desiccation. Toxoplasma oocysts are normally stored in $2 \%$ sulphuric acid and are unaffected even by treatment with sodium hypochlorite! Therefore, viable oocysts could easily contaminate the working environment. In addition, oocysts can infect by inhalation as an aerosol. Therefore, great care is required when grinding oocysts to obtain their contents. This stage is unique and, as such, should be treated with extreme caution to prevent laboratory infections!

Coinciding with the discovery of the life cycle in the 1960s, electron microscopy was developing as the "new technology" of the day and was only just being applied to a range of biological systems including parasites. In the case of Toxoplasma, it identified a complex polarized structure with a number of unique organelles (Fig. 1A), as well as characterizing a unique form of asexual proliferation termed endodyogeny (Sheffield \& Melton 1968, Vivier 1970). However, independent studies identified similar organelles in what were, at that time, thought to be unrelated parasites such as Plasmodium species and Eimeria species (Scholtyseck \& Melhorn 1970). These observations on the life cycle combined with the comparative ultrastructural studies, led to the proposal of a major change in the classification of the Protozoa with the creation of a new Phylum incorporating what had previously been thought to be very disparate parasites. The Phylum Apicomplexa was proposed containing many parasites of human and veterinary importance such as the genera Babesia. Theileria, Plasmodium, Eimeria, Toxoplasma, Neospora and Cryptosporidium (Levine et al. 1980). The name emphasizes the important role played by comparative electron microscopy. It was now possible to show a close relationship between parasites causing important human diseases such as malaria, toxoplasmosis and cryptosporidiosis.

The recognition of Toxoplasma as a human pathogen increased during the 1970s with immuno-suppressant treatment being used following organ or bone marrow transplants and in the treatment of certain neoplastic disease (Cohen 1970, Ruskin \& Remington 1976). This was further compounded by the appearance of the acquired immuno-deficiency syndrome (AIDS) epidemic in the late 1970s, where Toxoplasma was an important opportunistic infection (Horowitz et al. 1983, Luft et al. 1984, Velimirovic 1984, Navia et al. 1986, Israelski \& Remington 1988). The vast majority of cases of toxoplasmosis in immuno-compromised patients are believed to result from recrudescence of a chronic infection rather than resulting from a new infection (Gallino et al. 1996). Humans and Toxoplasma have evolved an excellent host parasite relationship and, as long as both parties stick to the rules, disease is rare but the parasite relies on the host having a competent immune system. It is believed that the rupture of a tissue cyst will release hundreds of 
bradyzoites that will by default convert to tachyzoites. These tachyzoites undergo rapid proliferation in the absence of an effective immune response, resulting in progressive host tissue destruction (necrotic lesions) and systemic dissemination, leading to rapid death of the host (Fig. 12F, G). However, the tachyzoites can be effectively treated and rapidly killed by administration of pyrimethamine and sulphadiazine. This treatment must be initiated as quickly as possible to minimize the tissue destruction resulting from tachyzoite proliferation in immuno-compromised patients the motto should be, "treat first and confirm the diagnosis later". Unfortunately, the treatment has no effect on the remaining tissue cysts and after withdrawal of the treatment additional recrudescences can occur. This treatment is not ideal for long term use for a number of reasons, including bone marrow toxicity associated with pyrimethamine and allergy to sulphadiazine. To date, there is no drug available that will destroy all the bradyzoites within tissue cysts. This means it is impossible to eradicate the infection from an individual. Any drug that proved to be effective against the tissue cyst would represent a major advance. It would be possible to eradicate the parasite prior to transplantation or treatment for neoplastic disease and prevent repeated recrudescence in AIDS patients. It has been observed that after a number of treatments for repeated recrudescence, drug resistance may develop (unpublished observations). Fortunately the development of drug resistance is unlikely to be a problem in toxoplasmosis, since all the drug resistant parasites die with the host.

The 1970 s/80s saw a markedly increased volume of Toxoplasma research and a move away from basic parasitology and human disease into specialist areas such as immunology, molecular biology and genetics. The ease with which the tachyzoite of Toxoplasma can be maintained indefinitely in tissue culture made it an excellent model for examining molecular changes and facilitated the identification of the molecular mechanism involved in the various processes associated with parasite development. It also made it a good model for research into the Apicomplexa in general. Among the first to utilize the new knowledge was Elmer Pfefferkorn and colleagues who, using mutagenic techniques, characterized parasites displaying different drug resistance and auxtrophic markers and then used the sexual development in the cat to carry out crosses between different strains (Pfefferkorn et al. 1977, Pfefferkorn \& Pfefferkorn 1977, 1979, 1980). These studies confirmed the Mendelian inheritance, the haploid nature of the parasite and the ability of a cloned parasite to give rise to the complete sexual cycle.

The last 30 years have produced a deluge of progressively more detailed information on all aspects of the biology of the parasite and its interrelationship with its host cell. There have been advances in our understanding and treatment of human disease and the immune response that will be discussed elsewhere and will not be included in this review. There have been major technical advances in our ability to identify individual proteins and gene sequences and to manipulate the genome to further our understanding of the molecular aspects of parasite development. It started in the early 1980 s with the identi- fication of specific antibodies in conjunction with newly developed immunocytochemical techniques employing enzymatic (peroxidase) or fluorescent markers to identify the expression and localisation of proteins recognised by the specific antibody. The specificity of the antibodies was initially improved by the use of monoclonal antibodies and later by the production of polyclonal antibodies to recombinant proteins. The availability of useful reagents has been advanced by continued technical improvement in our ability to manipulate the parasite genome. This has rapidly progressed from the first description of cloning of individual genes (Burg et al. 1988, Cesbron-Delauw et al. 1989) through the development of techniques to facilitate transfection with selectable markers for allelic replacement (including generation of "knock-outs") and complementation (Donald \& Roos 1994, Kim et al. 1993, Soldati \& Boothroyd 1993, Roos et al. 1994, Sibley et al. 1994, Soldati et al. 1995). With the ability to stimulate stage conversion from tachyzoite to bradyzoites in vitro, it was possible to identify molecules specifically expressed by the different stages (Bohne et al. 1996). To date, a number of tachyzoite and bradyzoite specific markers have been identified that can be used to follow the developmental changes in the intermediate host to further our understanding of "normal" development (Ferguson 2004). Another advance was the application of green fluorescent protein (GFP) technology to Toxoplasma (Striepen et al. 1998). The ability to incorporate the sequence for the fluorescent GFP into the gene of the protein of interest allowed protein expression to be followed during development in live cells in vitro by following the fluorescent signal. There are now a repertoire of genes and markers with which to follow localisation of proteins to any of the parasite organelles and to start to identify the sequences involved in organelle targeting (Striepen et al. 2001, 2007, Joiner \& Roos 2002, Gubbels \& Striepen 2004).

The rate of gene discovery was increased with the development of expression sequence tags (ESTs) (Ajioka et al. 1998). When ESTs from different parasite stages were examined, it was possible to confirm and expand the identification of genes showing stage specificity. Many hundreds of ESTs from different stages are now available on the website (www.toxoDB.org). It is worth noting that while there are ESTs for tachyzoites, bradyzoites and oocysts (sporozoites), there are no ESTs of the coccidian (asexual and sexual) stages. At this time, techniques were developed to make sequencing of the complete genome of an organism possible and Toxoplas$m a$ has been selected for sequencing. This is an ongoing project and the updated information is available on a specific website: www.toxoDB.org (Gajria et al. 2008).

Since 2000, there has been the application of proteomics to Toxoplasma (Cohen et al. 2002). It is possible to separate proteins by electrophoresis and identifying individual proteins using mass spectrometry (Cohen et al. 2002). In Toxoplasma this can be applied to the whole organism or to particular sub-sets, such as excretedsecreted proteins (Zhou et al. 2005) or rhoptry proteins (ROPs) (Bradley et al. 2005). This has facilitated the identification of large numbers of new proteins. In studies of the complete parasite, it is believed that proteomic 
data will assist in complimenting the genomic data and improve gene identification (Xia et al. 2008).

A new avenue of research was opened up in the mid 1990 s with the identification of a plastid-like DNA within members of the Apicomplexa (Wilson et al. 1996). In 1996, a structure of unknown function, previously called the Golgi adjunct or multi-membranous vacuole, was identified as the plastid (McFadden et al. 1996, Kohler et al. 1997) (Figs 1B, 9C). This was based on ultra structural in situ hybridization using specific DNA sequences originally identified in the extra-nuclear DNA of Plasmodium falciparum (Wilson et al. 1996). The organelle is characterized by being enclosed by four membranes (Fig. 1D). This arrangement was thought to represent evidence of secondary endosymbiosis (Kohler et al. 1997). The plastid, which has become know as the apicoplast, is present in all members of the Apicomplexa, with the exception of the genus Cryptosporidium. In plastid bearing Apicomplexa studied to date, it is essential for parasite viability and, therefore, has created much interest as a new target for anti-apicomplexan drugs (Fichera \& Roos 1997).

Another major advance in the 1990s was the development of techniques that allowed the population structure of Toxoplasma to be investigated. There have been many strains of Toxoplasma isolated over the years that showed marked differences in their behaviour within mice but their interrelationships were unknown. Two techniques were initially developed that allowed the relationships of the various strains to be compared. The first was the identification of a number of specific isoenzymes (Darde et al. 1992, Darde 1996) and the second was based on comparing restriction fragment length polymorphisms (Sibley et al. 1992). There was good correlation between the two techniques (Darde 1996). These techniques allowed a large number of strains to be compared and identified with some unexpected findings. The strains from Europe and North America were found to be extremely homogeneous belonging to just three genotypes (Types 1, 2 and 3) (Howe \& Sibley 1995). This was further refined using single nucleotide polymorphisms (Khan et al. 2005). The findings suggested that in North America and Europe there had been limited sexual crossing and that a single sexual cross approximately 10,000 years ago may have given rise to the three major clonal lineages with a selective advantage resulting in their domination ( $\mathrm{Su}$ et al. 2003, Boyle et al. 2006, Khan et al. 2006a). Using a slightly different technique, an alternative explanation for the global population structure has been proposed base on isolates from a single host species (chickens) (Lehmann et al. 2006). However, what is becoming very clear is that the parasite population profile in South America diverges markedly from the picture seen in Europe/North America (Khan et al. 2006a, b, 2007). In terms of human infection, in Europe/North America the majority of cases of human toxoplasmosis was associated with Type 2 strains with low levels of Type 1 and 3 (Howe et al. 1997). In contrast, in South America, a much higher incidence of Type 1 strains were identified in both clinical and asymptomatic cases (Ferreira et al. 2008). In addition, there were an increased number of exotic (non-Type
1-3) strains although there was also evidence of limited sexual crossing. In the case of human disease, it was noted that there were marked differences between South America and Europe/North America and this does appeared to correlate with the higher incidence of Type 1 strains. This has implications for understanding human disease due to the marked differences in pathology and morbidity of infection in South America compared to Europe/North America and will be an important area for future research (Vallochi et al. 2005, Peyron et al. 2006, Morisset et al. 2008).

Recently there has been renewed interest in possible behavioural changes associated with chronic infection with T. gondii. As Bill Hutchison used to say: "Any organism that shares our brain with us is worthy of study". It makes sense that a parasite requiring to be eaten by a definitive host would benefit by changing the behaviour of its host to increase the chances of being ingested. Early studies in mice showed that infection did appear to have effects that may increase predation (Webster 2007) and, in more recent studies in rats, it has been shown that this change may be more specifically related to reducing the rat's innate fear of cats (Webster 2007). This has been confirmed in studies in both mice and rats (Vyas et al. 2007). However, the problem arises when the role of chronic infection on human behaviour is investigated. There have been a number of reports that schizophrenics have a significantly higher incidence of chronic Toxoplasma infection (Torrey et al. 2007). I would argue that it would have been more surprising if schizophrenics had not had an increased incidence due to their behavioural changes increasing their risk of infection. Two arguments have been put forward in support of a role for chronic Toxoplasma infection. The first is that treatment with anti-Toxoplasma drugs shows an improvement in their symptoms therefore supporting a role for $T$. gondii infection (Webster et al. 2006, Torrey \& Yolken 2007). The second is that certain anti-psychotic drugs are active against Toxoplasma tachyzoites in vitro (Jones-Brando et al. 2003, Webster et al. 2006, Torrey et al. 2007). However, both arguments have flaws. Firstly, treatment for Toxoplasma involves powerful drugs that will have multiple effects on host physiology. Secondly, the in vitro observations on drug effects have to be treated with caution. For example, it was shown that valproic acid (a mood-stabilizing agent) had no effect on tachyzoites or bradyzoites in vivo (Goodwin et al. 2008). It has been known for many years that chronic infections with bradyzoites within tissue cyst are refractile to all known treatment regimes. Therefore, it is difficult to understand what effect the treatments could be having on the chronic infection. None of these studies show a direct effect of infection with Toxoplasma on the development of schizophrenia. What is required is the identification of a random cohort of uninfected individuals where a number of individuals (half) within the group subsequently become infected. Then, by comparing the subsequent incidence in schizophrenia in the two groups, a more accurate estimate of the role of Toxoplasma may be obtained. So, while I am still sceptical about the role of chronic Toxoplasma infection in schizophrenia or any 
other neurological disorders, I will keep an open mind until proper control studies have been performed.

As a final homage to Nicolle, Manceaux and Splendore, I would like to summarise how this new molecular data can be combined with morphological techniques to increase our understanding of the in vivo development of $T$. gondii in both the intermediate and definitive host. Using immuno-light and electron microscopy, it is possible to study the expression and localisation of specific proteins during the development of the parasite in both the definitive and intermediate host (Ferguson 2004).

It has been possible in the various infectious stages (tachyzoites, bradyzoites, merozoites and sporozoites) to localise specific proteins to the various apical organelles such as the micronemes (Fig. 1B, C) and dense granules (Fig. 1E) and, with the recent identification of the rhoptry proteome (Bradley et al. 2005), it is possible to localise protein to either the body (ROPs) (Fig. 1F) or the neck (Fig. 1G) of the rhoptries. Using double labelling it is possible to identify proteins located in different organelles (Fig. 1H). These results have lead to an improved understanding of how the infectious form identifies and invades a host cell and how the protective parasitophorous vacuole (PV) is formed (Joiner \& Roos 2002, Dubremetz 2007, 2008, Boothroyd \& Dubremetz 2008, Carruthers \& Tomley 2008).

\section{Host parasite relationship - structure of the PV}

In addition, it has been possible to show that the host parasite relationship is markedly different between the various developmental stages. The tachyzoite was located within a loose PV limited by a unit membrane from which a network of tubules protruded into the vacuole, while host cell mitochondria and rough endoplasmic reticulum (rER) collected around the limiting membrane of the vacuole (Fig. 5A). It was observed that the various dense granules proteins were involved with the PV during tachyzoite development (Ferguson 2004, Mercier et al. 2005). In the case of the bradyzoite, there were identifiable structural and molecular differences in the vacuole associated with tissue cyst formation (Ferguson 2004). It is limited by an undulating unit membrane but lacks the intra-vacuolar tubular network and the associated host cell $\mathrm{rER}$ and mitochondria. However, it is characterised by a homogenous layer of material that contains specific tissue cyst wall proteins (Fig. 5B). The most significant differences were seen in the coccidian stages. The PV is limited by a thick laminated structure consisting of three closely applied unit membranes. There is no accumulation of any host cell organelles around the PV membrane. In addition, it is a close fitting structure with cone-like protuberances, which may interact with the parasite plasmalemma (Fig. 3C). The vacuoles lack any evidence of tubular-membrane structures. Furthermore, these morphological differences have been confirmed at the molecular level where immunocytochemical studies showed the absence of expression of the majority of dense granule proteins (Fig. 8D-F) (Ferguson et al. 1999, Ferguson 2004). To date, GRA7 and NTPase been identified with no evidence for the expression of the other GRA proteins: GRA1 - 6 and 8 (Ferguson 2004).

\section{Comparison of the asexual division - endodyogeny and endopolygeny}

Within the Apicomplexa, there are four forms of asexual multiplication: classical schizogony, endodyogeny, Toxoplasma endopolygeny and Sarcocystis endopolygeny (Fig. 6). These vary in the number of DNA replications, nuclear divisions and the location of daughter formation. The majority of apicomplexan parasites undergo schizogony involving a proliferative phase of repeated nuclear divisions followed by daughter formation associated with the surface of the parasite. In contrast, within the cyst forming Coccidia, three variations have been identified, all involving formation of the daughters within the mother cell cytoplasm. The first is associated with the formation of two daughters (endodyogeny). While in the second there is a proliferative phase with repeated nuclear divisions followed by the formation of daughters within the mother cell (Toxoplasma endopolygeny) (Fig. 7). The third is undergone by certain asexual stages of Sarcocystis and involves repeated cycles of DNA replication but no nuclear division. The daughters

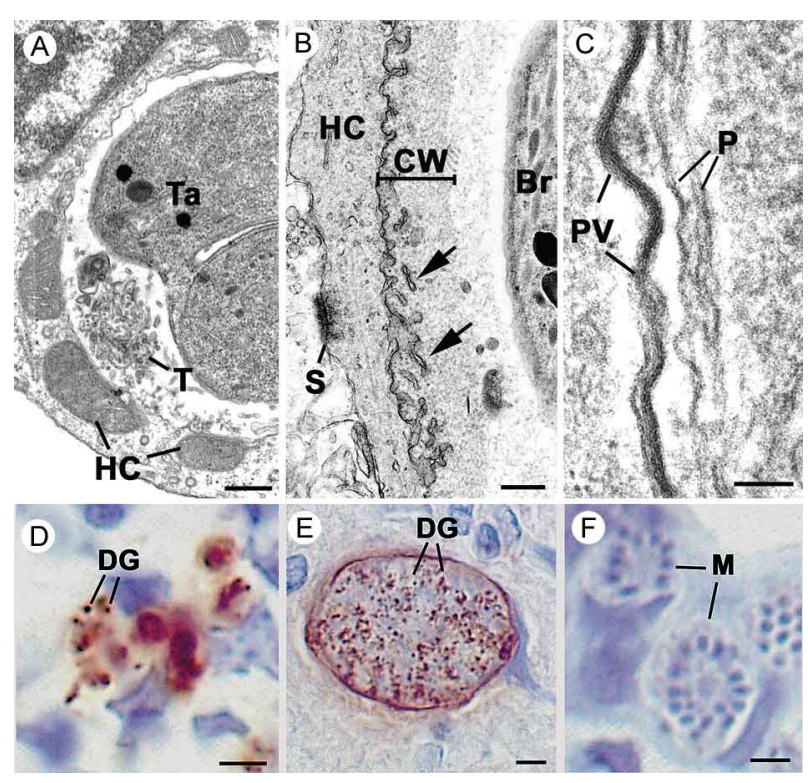

Fig. 5: comparison of the structure of the parasitophorous vacuole by TEM (A-C) and expression of GRA6 identified by immuno-cytochemistry using peroxidise as chromogen (D-F) in the tachyzoite $(\mathrm{A}, \mathrm{D})$, the tissue cyst $(\mathrm{B}, \mathrm{E})$ and the coccidian stage $(\mathrm{C}, \mathrm{F})$ of Toxoplasma gondii. Bars $=200 \mathrm{~nm}(\mathrm{~A}, \mathrm{C})$ and $5 \mu \mathrm{m}(\mathrm{D}-\mathrm{F})$. A: cross section through a tachzyoite developing within a monocyte showing the loose parasitophorous vacuole to be limited by a unit membrane around which host cell mitochondria (HC) congregate, while the vacuole contains a tubular network (T); Ta: tachyzoite; B: periphery of a tissue cyst showing cyst wall limited by a membrane with invaginations (arrows) into the homogenous material forming the cyst wall (CW). The host cell can be identified as a neurone based on the presence of a synapse (S); Br: bradyzoites; $\mathrm{C}$ : detail from the periphery of a developing coccidian stage from a cat showing the tight parasitophorous vacuole $(\mathrm{PV})$ to be limited by a thick laminate membrane; P: parasite pellicle; D-F: sections showing tachyzoite development in the lung (D) and tissue cyst in the brain (E) showing positive staining of the dense granules (DG) and parasitophorous vacuole or cyst wall while in F, the merozoites (M) formed by coccidian development are negative. 
form internally and are associated with fragmentation of the polyploidy nucleus (Sacrocystis endopolygeny) (Heydorn \& Mehlhorn 1978, Speer \& Dubey 1981). The tachyzoites and bradyzoites divide exclusively by endodyogeny, giving rise to two daughters (Fig. 5). However, it was noted that repeated cycles of endodyogeny could occur. It has been observed that this occurred more frequently in mice infected with avirulent stains (Ferguson \& Hutchison 1981). In contrast, the form of asexual development undergone by the coccidian stages is Toxoplasma endopolygeny (Fig. 7) resulting in the formation of between eight-30 daughters (Fig. 3A-C). Since the number of nuclear divisions prior to daughter formation can vary, the number of merozoites produced can also vary. Examination of well over a thousand schizonts by electron microscopy has failed to reveal a single developmental stage that could not be fitted into the process of Toxoplasma endopolygeny. Recently, an ultrastructural study has described a number of "types" (B-E) of schizonts, some of which were only observed at the early stages of infection (Speer \& Dubey 2005). It is possible that type B represents tachyzoite development, given the host parasite relationship and multiplication by repeated endodyogeny. Therefore, rather than representing early coccidian stages, it is possible that they represent a sub-population of invading bradyzoites that have defaulted to tachyzoite development. In the case of type C-E schizonts, the parasites show typical features of endopolygeny, differing only in size and number of daughters formed. Since there is no fundamental difference in the biological process, little is gained by the sub-division.

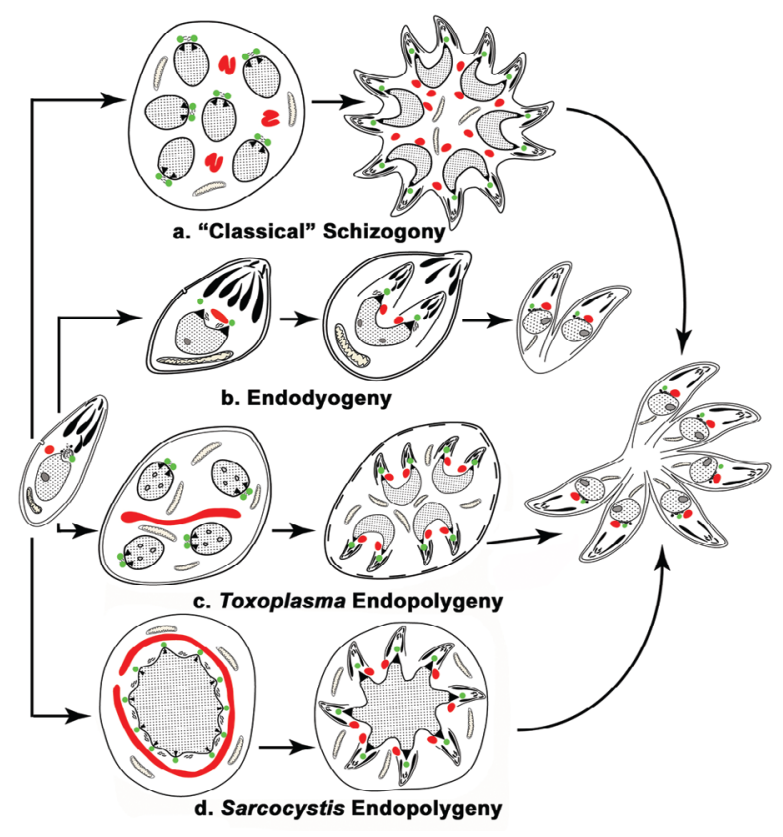

Fig. 6: diagram summarising the differences in timing of nuclear division and the location of daughter formation in the four forms of asexual proliferation undergone by apicomplexan parasites. The coccidian stages of Toxoplasma gondii employ Toxoplasma endopolygeny, while the tachyzoites and bradyzoites undergo endodyogeny (Ferguson et al. 2007, with permission).

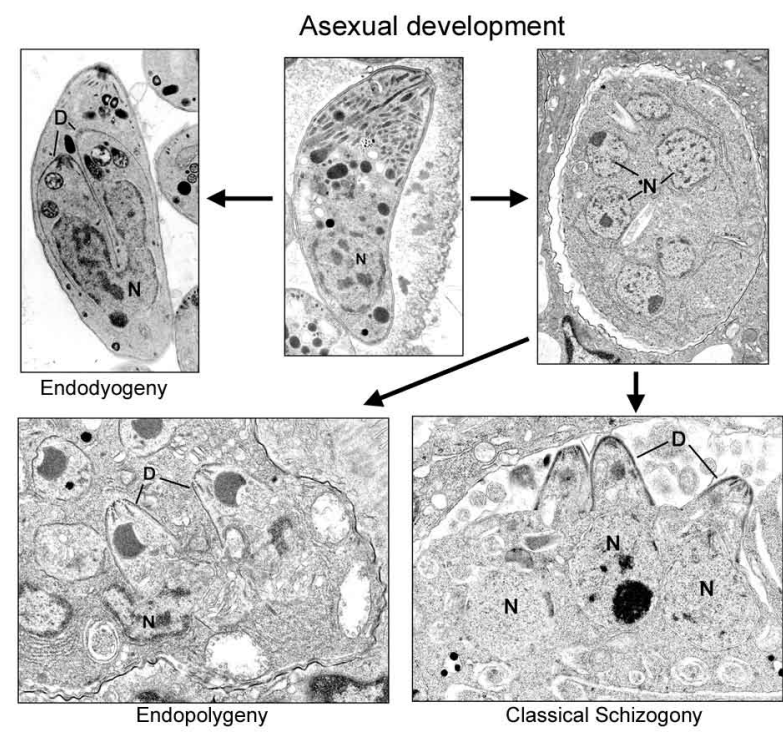

Fig. 7: composite using a series of electron micrographs to summarise the processes of asexual multiplication within Toxoplasma and classical schizogony.

\section{Sexual development in the definitive host}

The mature merozoites formed by endopolygeny are released, can invade new enterocytes and undergo a repeated cycle of asexual development or differentiate into a sexual stage; either microgametocyte or macrogametocyte. The factors involved in deciding the fate of a merozoite are unknown. It is clear that the initial asexual cycles are required to increase parasite density for two reasons. The first is that, if the sexual process is to be successful, the male and female gametes have to be able to find each other. Secondly, since each macrogamete only produces a single oocyst, there requires being literally millions of merozoites available to develop into macrogametes to produce the large number (millions) of oocysts seen in the faeces.

The terms microgamont and microgametocyte are synonymous and refer to the developing parasite from which 16-30 microgametes develop. This process is identical across the Coccidia (Scholtyseck et al. 1972) and is shown diagrammatically (Fig. 8A). There is an initial proliferative phase with repeated nuclear division. This is followed by movement of the nuclei toward the periphery and marked peripheral condensation of the chromatin. The microgamete is formed by a budding of a portion of cytoplasm containing two basal bodies, from which long flagella grow, the electron dense portion of the nucleus and a mitochondrion (Fig. 8B) (Ferguson et al. 1974, Dubey et al. 1998). The mature microgametes detach from the residual cytoplasm and appear as elongated structure with an electron dense nucleus anterior to which is the mitochondrion and the basal bodies of the two flagella (Fig. $8 \mathrm{C}, \mathrm{D})$. It is because of the basic similarity to a sperm cell that the use of the term male gamete seems appropriate. Recently it has been shown that MORN1 located at the 


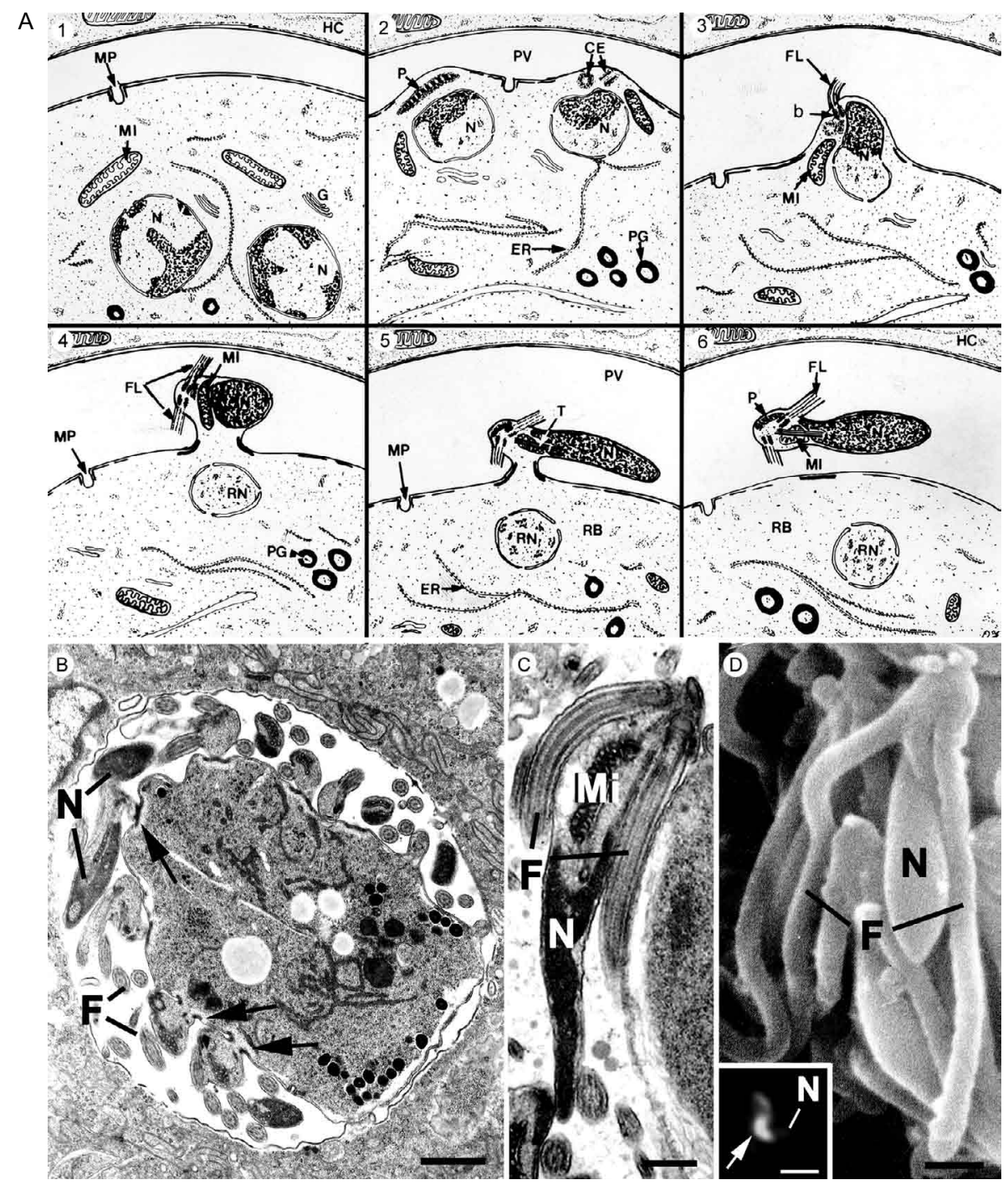

Fig. 8A: diagram summarising the structural changes observed during formation of the microgamete. 1: end of proliferative phase; 2 : movement of the nuclei the periphery and chromatin condensation; 3: Flagella start to form from basal bodies and dense portion of nucleus and associated mitochondrion begin to protrude form the surface; 4 : the basal bodies, nucleus and mitochodrion continue to protrude from the microgametocyte; 5: microgamete matures while still attached by its anterior end to the mother cells; 6 : mature microgametes released into parasitophorous vacuole; b: basal body; Ce: centriole; ER: endoplasmic reticulum; FL: flagellum; MI: mitochondrion; MP: micropore; N: nucleus; P: perforatorium; PG: polysaccharide granule; PV: parasitophorous vacuole; RB: residual body; RN: residual nucleus; T: microtubules; B: electron micrograph of a mid stage microgametocyte showing the microgametes budding from the surface of the mother cell (arrows); F: flagellum; N: nucleus. Bar $=1 \mu \mathrm{m} ; \mathrm{C}, \mathrm{D}$ : transmission (C) and scanning (D) electron micrographs of the mature microgamete showing the two long flagella (F) and the elongated nucleus $(\mathrm{N})$ and mitochondrion $(\mathrm{Mi})$. Bars $=100 \mathrm{~nm}$; insert: immuno-fluorescent image showing the anterior of the microgamete positively stained for MORN1 (green). Bar $=100 \mathrm{~nm}$.

point of budding, is present in the anterior of the microgamete (Fig. 8D insert) and represents the first marker for the microgamete (Ferguson et al. 2008).

Again, the terms macrogamont and macrogametocyte are synonymous and maturation gives rise to a single macrogamete. The macrogametocyte has two very important functions. It has to synthesise and store all the nutritional requirements to allow sporulation in the external environment and sustain the viability of the sporozoites over long periods (in excess of 1 year). Secondly, it has to synthesise the specific components necessary to form the oocyst wall. Therefore, during development, there is no nuclear division but, as the parasite grows, large numbers of polysaccharide granules and lipid droplets are synthesised and stored in the cytoplasm. In addition, specific structures that will subsequently be involved in oocyst wall formation can be identified. A large number of electron dense granules are formed as well as electron dense deposits within the rough endoplasmic reticulum termed wall forming bodies Type 2 (WFB2) (Fig. 9A, B) (Ferguson et al. 1975, Dubey et al. 1998). It was only possible using immunocytochemisty to identify two types of granules - the veil forming bodies and wall forming bodies Type 1 (Ferguson et al. 2000) (Fig. 9D). 
The mature macrogametocyte can be referred to as the macrogamete and possess a single nucleus and large apicoplast, in addition to the above organelles (Fig. 9A, C).

The oocyst wall is a unique structure providing the parasite with physically strong and chemically impervious layers protecting it from the rigour of the external environment. However, oocysts are sensitive to heat and desiccation. The oocyst wall, like other members of the Coccidia, has a multilayer structure. There is the thin outer veil formed during maturation by secretion of the veil forming bodies. This is followed by simultaneous secretion of the WFB1, which polymerizes to form a thin electron dense outer layer of the oocyst wall proper. At this point, the material of the WBF2 is transported from the rER via Golgi vesicles and secreted where they form the electron lucent inner layer (Belli et al. 2006) (Fig. 9E, F). Unfortunately, the impervious nature of the oocyst wall prevents the penetration of chemicals required for electron microscopy and prevents detailed analysis of sporulation.

\section{Development in the intermediate host}

It has been possible using immuno-histology and stage specific antibodies to follow the distribution of the parasite during the development of the acute phase in orally infected mice and identify the changes associated with conversion from the acute to the chronic phase (Ferguson \& Hutchison 1987b, Dubey 1997a, Dubey et al. 1997). Recently, it has been possible to track parasites in live mice by using Fire-fly luciferase expressing parasites (Saeij et al. 2005, Boyle et al. 2007). In routine haematoxylin and eosin stained sections, it is very difficult to identify individual parasites (Fig. 10A) but, immuno-staining of sections using either peroxidase (Fig. 10B) or fluorescein isothiocyanate (Fig. 10C) as a marker, allowed individual parasite to be easily resolved. Using the stage specific markers SAG1 (tachyzoite specific) and BAG1 (bradyzoite specific), it was possible to follow the changes associated with the acute phase and conversion into the chronic phase. During the early

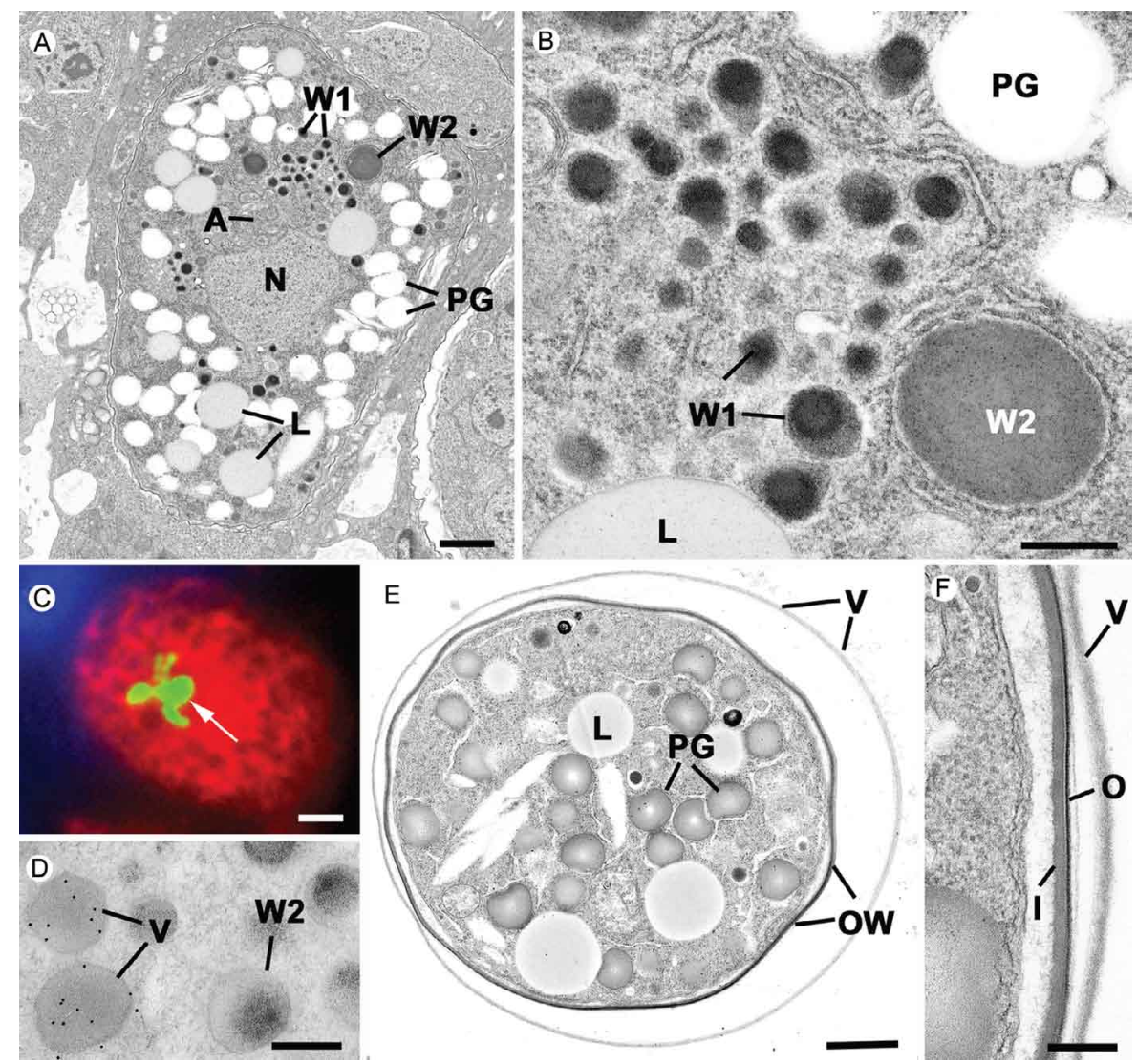

Fig. 9A: low power of a mature macrogametocyte/macrogamete showing the central nucleus $(\mathrm{N})$ with an adjacent apicoplast (A) and cytoplasm packed with polysaccharide granules (PG), lipid droplet (L) numerous small wall forming bodies Type 1 (W1) and a few larger wall forming bodies Type $2(\mathrm{~W} 2)$. Bar $=1 \mu \mathrm{m}$; B: detail of part of the cytoplasm from fig. A showing the numerous small electron dense WFB1 (W1) and that the WFB2 are located within the rough endoplasmic reticulum. L: lipid droplet; PG: polysaccharide granule. Bar = $200 \mathrm{~nm}$; C: macrogamete immuno-labelled with anti-enolase 2 (red) and anti-enoyl reductase (green) showing the cytoplasm stained for enolase 2 and the large branched apicoplast stained for enoyl reductase (arrow). Bar $=1 \mu \mathrm{m}$; D: immuno-electron micrograph of a macrogametocyte stained with anti-MIC4 showing the dense granules could be separated into two groups; the immuno-stained veil forming bodies (V) and the negative WFB1 (W1). Bar $=100 \mathrm{~nm}$; E: low power of an oocyst showing the cytoplasmic mass containing polysaccharide granule (PG) sand lipid droplets (L) enclosed by the loose outer veil $(\mathrm{V})$ and oocyst wall $(\mathrm{OW})$. Bar $=1 \mu \mathrm{m} ; \mathrm{F}$ : detail from the periphery of the oocyst in E showing the outer veil (V) and the electron dense outer layer (O) and the electron lucent inner layer (I) of the oocyst wall. Bar $=100 \mathrm{~nm}$. 
stages of infection tachyzoites were observed initially in the lymph nodes, spleen and lungs (Fig. 10A). This showed rapid proliferation of the tachyzoite and dissemination to all organs of the body including the brain and heart by 10 days post infection (pi). Between 12-15 days $\mathrm{pi}$, there was evidence of stage conversion of tachyzoite to bradyzoites. There appeared to be marked tissue tropism with cyst formation occurring predominately in the brain of the mouse (Fig. 10D, E). No evidence of stage conversion was observed in any other organ, including the heart. However, this may vary between host species, with the majority of tissue cysts found in the muscles in the cat (Dubey 1997b). In the brain between 12-15 days pi, it is possible to identify both tachyzoites and early tissue cysts by immunocytochemistry and electron microscopy within the brain lesions (Fig. 10D) due to the structure of the PV and the presence of a tissue cyst wall specific protein recognised by antibody $\mathrm{CC} 2$ (Gross et al. 1995) containing early BAG1+ bradyzoites (Fig. 11B). Using double labelling techniques, it was possible to show that individual parasites could express both tachyzoite and bradyzoite antigen simultaneously (Fig. 10E). However, not all the tachyzoites entering the brain converted to bradyzoites. A number continued to proliferate as tachyzoites before being destroyed by the immune response, similar to that seen in other organs. By day 21 it was difficult to find any tachyzoites
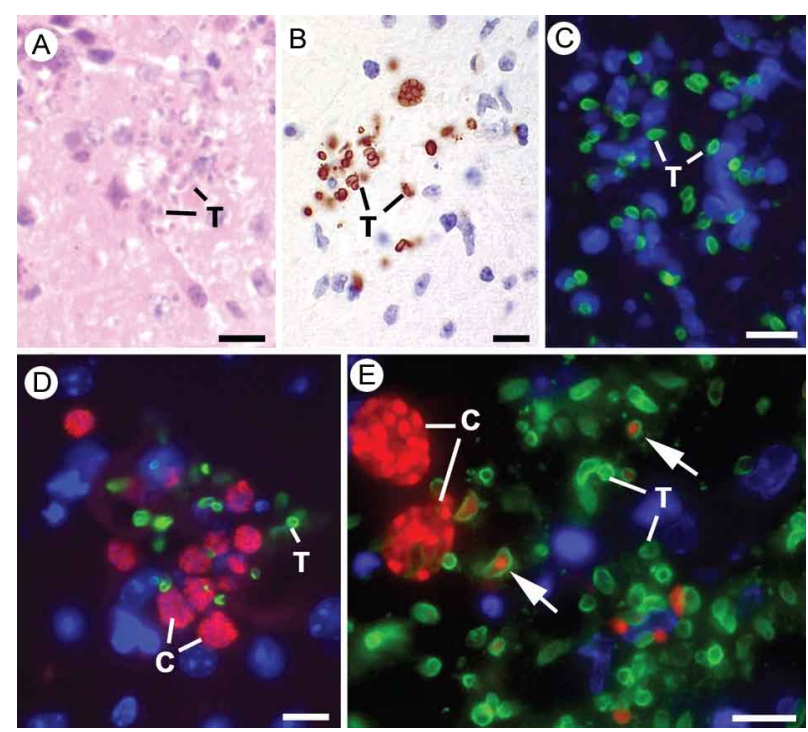

Fig. 10A, B: section through the brain of a mouse showing the difficulty identifying tachyzoites in H\&E stained section (A) compared to an immuno-stained section using peroxidase as chromogen and antiSAG1 (B). The tachyzoites (T) are easily seen in the immuno-stained section; C: section through a lymph node stain by immuno-florescence and tachyzoite specific anti-SAG1 (green) showing the numerous SAG1+ tachyzoites (T); D, E: double labeled immuno-fluorescent images of brain lesions at 14 days post-infection showing stages conversion between tachyzoites (T) (green) and bradyzoites (red) within tissue cysts $(\mathrm{C})$. Note a few individual parasites positive for both markers (arrows). Bar $=10 \mu \mathrm{m}$; D: is labeled with anti-SAG1 (green) and anti-BAG1 (red) while E is labeled with anti-SAG1 (green) and anti-Enolase 1 (red). in the brain or other organs. The trigger responsible for certain tachyzoites in the brain to enter new cells and develop into bradyzoite containing tissue cysts is not fully understood but, it is possible that a subpopulation of tachyzoites are predestined to convert to bradyzoites, when entering the correct host cell. This would be consistent with the observation that a small sub-population of tachyzoites contained vacuoles positive for the cyst wall protein (Gross et al. 1995). It appears that tissue cyst development was initiated at the time of parasite entry with the formation of a distinctive vacuole. Within the early tissue cyst, a large proportion of the organisms were dividing by endodyogeny but the proportion of dividing organisms was reduced with time and, after three months, it was difficult to find evidence of bradyzoite division (Ferguson \& Hutchison 1987b). Examining tissue cysts over the natural life of the host ( 2 years for the mouse) showed that the tissue cysts were always located within viable host cells (Fig. 11C). It is not always possible to identify the host cell from the thin rim of host cell cytoplasm visible. However, it was possible in the majority of cases to show conclusively that the host cell was a neurone, based on the presence of synapses (Figs 5B, 11D) (Ferguson \& Hutchison 1987a). While there

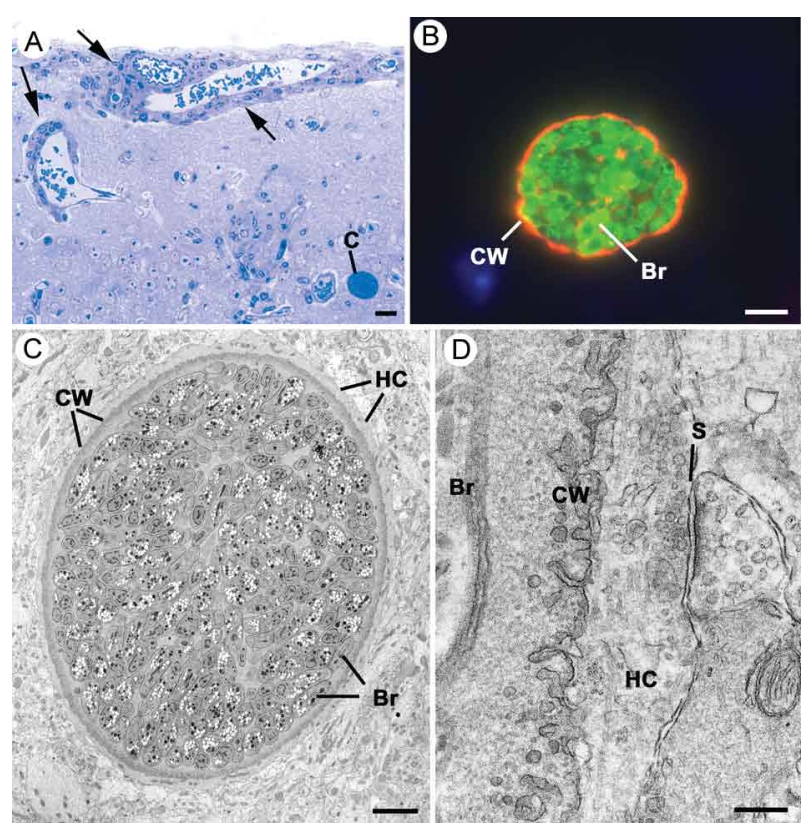

Fig. 11A: light micrograph of a section through the brain of a chronically infected mouse showing numerous inflammatory cells within the meninges and cuffing the blood vessels (arrows). Note the absence of inflammatory cells associated with the tissue cyst (C). Bar $=120 \mu \mathrm{m}$; B: section through a tissue cyst double with anti-BAG1 (green) and antibody $\mathrm{CC} 2$ (red) showing the bradyzoites $(\mathrm{Br})$ stained green and the tissue cyst wall $(\mathrm{CW})$ stained red. $\mathrm{Bar}=1 \mu \mathrm{m}$; $\mathrm{C}$ : low power electron micrograph through a tissue cyst in the brain of a mouse. The tissue cyst, containing large numbers of bradyzoites $(\mathrm{Br})$, is located within a host cell $(\mathrm{HC})$ and is enclose by a tissue cyst wall $(\mathrm{CW})$. Bar $=10 \mu \mathrm{m}$; $\mathrm{D}$ : detail of the periphery of the a tissue cyst showing the host cell (HC), which can be identified as a neurone by the presence of a synapse (S), and invagination of the limiting membrane into the ground substance of the cyst wall $(\mathrm{CW})$. Br: bradyzoite. Bar $=100 \mu \mathrm{m}$. 
was cuffing of the blood vessels by inflammatory cells, there was no reaction to the tissue cysts, which appear to be masked within the viable host cell (Fig. 12A). It has been proposed that individual bradyzoites may escape and form daughter tissue cysts, but this is inconsistent with my observations. I think this is unlikely for four reasons. The first is that groups of cysts of different sizes can be found from the earliest stages of infection. Secondly, when examined by electron microscopy, the bradyzoites in the various cysts are at the same stage of maturity - the smaller cysts do not contain immature or dividing bradyzoites (natural size variation). Thirdly, in vivo bradyzoites appear to default to tachyzoites on entering a new host cell although it has recently been report that bradyzoites can give rise to bradyzoites in cultured muscle cells (Guimaraes et al. 2008). Fourthly, any bradyzoite leaving the protection of its host cell will be attacked by the host inflammatory cells.

A major problem is that it is difficult to directly relate the data from experiments carried out using different inbred strains of mice. It is known that the strain of Toxoplasma can have an effect on the pathology of the infection. However, the behaviour of a given strain of Toxoplasma can vary markedly, depending on the genetic make up of the mouse strain being used. In certain mouse strains, there appears to be an inability of the host to clear the acute phase of the infection, resulting in death after three-four weeks. In others, there can be the rapid disappearance of cysts around 12-16 weeks. Therefore, only experiments carried out using the same strain of Toxoplasma and host can be directly compared.

It is known that recrudescence is a problem in the immuno-compromised individual, probably resulting from the rupture of a tissue cyst. The question was: "What happens in such a situation in an immuno-competent individual?". An extensive search, over a number of years in chronically infected immuno-competent mice, identified a few $(<1 \%)$ rupturing tissue cysts (Ferguson et al. 1989). It appears that death of the host cell unmasks the tissue cyst and results in an immediate response of the host inflammatory cells, predominately monocyte/macrophages but also neutrophils. These can be seen surrounding the apparently still intact cyst and subsequently invading through the ruptured cyst wall (Fig. 12A-D). These inflammatory cells were phagocyotising and destroying the bradyzoites. When examined by immunocytochemistry, it was confirmed that there were only bradyzoites present, with no evidence of conversion to tachyzoites (Fig. 12B). It would appear that the immune response is so efficient that all the bradyzoites are destroyed before they can enter new host cells and undergo tachyzoite development. The end result is the formation of a small inflammatory nodule with minimal tissue destruction. Compare this to what is seen in immunocompromised individuals where there is no evidence of an inflammatory cell infiltrate and the lesions consist of large numbers of proliferating tachyzoites (Fig. 12F, G).

After 40 years, I feel the more we learn about Toxoplasma, the more I realise how much we do not understand. Although there have been unbelievable advances in our knowledge at the genomic and proteomic levels,

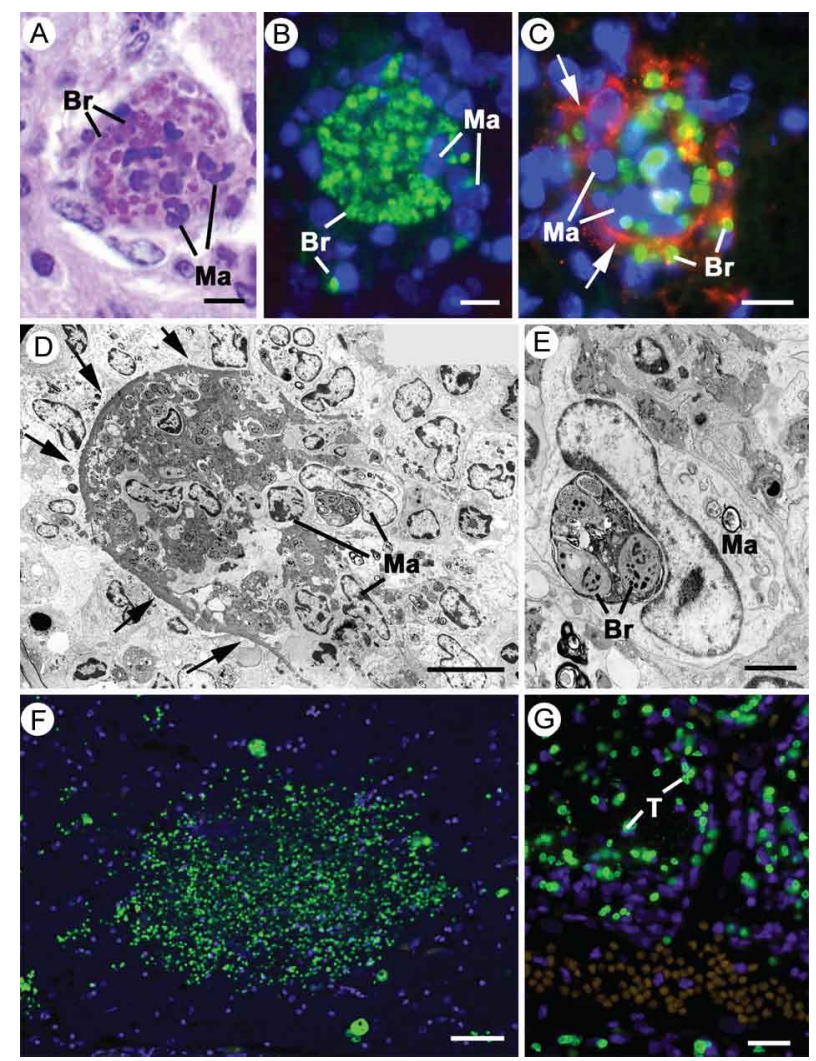

Fig. 12: light and electron micrographs of cyst rupture in immunocompetent mice (A-E) and light micrographs from an AIDS patient with recrudescent toxoplasmosis (F, G); A-C: sections through a ruptured tissue cyst stained with PAS (A), anti-SAG1 (red)/anti-BAG1 (green) (B) and anti-BAG1 (green)/antibody CC2 (red) (C). Note the macrophages (Ma) around and invading into the tissue cyst through ruptures in the cyst wall (arrows). Br: bradyzoites. Bars $=10 \mu \mathrm{m}$; D: electron micrograph of a section through a ruptured tissue cyst in an immuno-competent host showing the fractured cyst wall (arrows) partially enclosing the bradyzoites $(\mathrm{Br})$. Note the numerous macrophages $(\mathrm{M})$ surrounding and invading into the tissue cyst and phagocytising the bradyzoites. Bar $=5 \mu \mathrm{m}$; E: detail from D showing a macrophage (Ma) with bradyzoites $(\mathrm{Br})$ contained within a phagolysosome. Bar $=500 \mathrm{~nm} ; \mathrm{F}, \mathrm{G}$ : low power $(\mathrm{F})$ and detail $(\mathrm{G})$ of a section through the brain of an immuno-compromised patient double labeled with anti-SAG1 (green) and anti-BAG1 (red) showing large lesions containing very large numbers of tachyzoites $(\mathrm{T})$ resulting from recrudesence. Note the absence of any bradyzoites formation. Bars $=10 \mu \mathrm{m}$ and $1 \mu \mathrm{m}$, respectively.

all this has been based on those stages of the parasite associated with development in the intermediate host - the tachyzoite and bradyzoite. Toxoplasma could be considered to have a split personality: the gregarious outgoing sociable tachyzoite/bradyzoite that can develop in any cell of any warm-blooded animal (and cultured cell) and the reclusive, antisocial, coccidian stages that will only develop within cat enterocytes. To date, there have been no molecular studies on the coccidian stages - we have little or no idea of the specific genes and proteins associated with coccidian development. This is not unique to Toxoplasma but is a problem with studying all coccidian parasites. Since coccidian development must be related 
to changes in gene expression, then it would be a major advance if the factor controlling the expression of coccidian specific genes could be identified. It is for this reason that care should always be taken when extrapolating from observations based on the tachyzoite to the parasite as a whole. Too often I read, "Toxoplasma does X", when, what is really meant is that the, "tachyzoite of Toxoplasma does X", with no appreciation of the unique nature of coccidian development. An in vitro system for coccidian development would be a major step forward. We have been playing a game of chess with Toxoplasma for the last 100 years and we have made many advances. However, even with all our new knowledge, we are a long way from reaching "check mate". Therefore, I have no doubt that Toxoplasma will be a worthy opponent for the next 100 years.

\section{ACKNOWLEDGEMENTS}

To the large number of people I have collaborated with over the years and all those who have contributed tissue or reagents, without which I would have been unable to continue researching into Toxoplasma. I also thank to Jim Adjioka, Marc-Jan Gubbels, Craig Roberts, Nick Smith, JP Dubey, Andy McCo$1 \mathrm{~m}$ and Rima McLeod, for helpful discussion during the gestation of this review. It has been a daunting task writing this review and I apologise to all those authors of important works I have not included.

\section{REFERENCES}

Ajioka JW, Boothroyd JC, Brunk BP, Hehl A, Hillier L, Manger ID, Marra M, Overton GC, Roos DS, Wan KL, Waterston R, Sibley LD 1998. Gene discovery by EST sequencing in Toxoplasma gondii reveals sequences restricted to the Apicomplexa. Genome Res 8: 18-28.

Ajioka JM, Soldati D 2007. Toxoplasma molecular and cellular biology, Horizon Bioscience, Norfolk, 626 pp.

Belli SI, Smith NC, Ferguson DJP 2006. The coccidian oocyst: a tough nut to crack! Trends Parasitol 22: 416-423.

Bohne W, Parmley SF, Yang S, Gross U 1996. Bradyzoite-specific genes. In U Gross, Toxoplasma gondii, Springer-Verlag, Berlin, p. 81-91.

Boothroyd JC, Dubremetz JF 2008. Kiss and spit: the dual roles of Toxoplasma rhoptries. Nat Rev Microbio 6: 79-88.

Boyle JP, Rajasekar B, Saeij JP, Ajioka JW, Berriman M, Paulsen I, Roos DS, Sibley LD, White MW, Boothroyd JC 2006. Just one cross appears capable of dramatically altering the population biology of a eukaryotic pathogen like Toxoplasma gondii. Proc Natl Acad Sci USA 103: 10514-10519.

Boyle JP, Saeij JP, Boothroyd JC 2007. Toxoplasma gondii: inconsistent dissemination patterns following oral infection in mice. Exp Parasitol 116: 302-305.

Bradley PJ, Ward C, Cheng SJ, Alexander DL, Collar S, Coombs GH, Dunn JD, Ferguson DJ, Sanderson SJ, Wastling JM, Boothroyd JC 2005. Proteomic analysis of rhoptry organelles reveals many novel constituents for host-parasite interactions in Toxoplasma gondii. J Biol Chem 280: 34245-34258.

Burg JL, Perelman D, Kasper LH, Ware PL, Boothroyd JC 1988. Molecular analysis of the gene encoding the major surface antigen of Toxoplasma gondii. J Immunol 141: 3584-3591.

Carruthers VB, Tomley FM 2008. Microneme proteins in apicomplexans. Subcell Biochem 47: 33-45.
Cesbron-Delauw MF, Guy B, Torpier G, Pierce RJ, Lenzen G, Cesbron JY, Charif H, Lepage P, Darcy F, Lecocq JP, Capron A 1989. Molecular characterization of a 23-kilodalton major antigen secreted by Toxoplasma gondii. Proc Natl Acad Sci USA 86: 7537-7534.

Cohen AM, Rumpel K, Coombs GH, Wastling JM 2002. Characterisation of global protein expression by two-dimensional electrophoresis and mass spectrometry: proteomics of Toxoplasma gondii. Inter J Parasitol 32: 39-51.

Cohen SN 1970. Toxoplasmosis in patients receiving immunosuppressive therapy. JAMA 211: 657-660.

Darde ML 1996. Biodiversity in Toxoplasma gondii. In U Gross, Toxoplasma gondii, Springer-Verlag, Berlin, p. 27-41.

Dardé ML, Bouteille B, Pestre-Alexandre M 1992. Isoenzyme analysis of 35 Toxoplasma gondii isolates and the biological and epidemiological implications. J Parasitol 78: 786-794.

Desmonts G, Couvreur J, Alison F, Baudelot J, Gerbeaux J, Lelong M 1965. Etude epidemiologique sur la toxoplasmose: de l'influence de la cuisson des vidandes de boucherie sue la frequence de l'infection humaine. Rev Fr Etudes Clin Biol 10: 952-958.

Donald RG, Roos DS 1994. Homologous recombination and gene replacement at the dihydrofolate reductase-thymidylate synthase locus in Toxoplasma gondii. Mol Biochem Parasitol 63: 243-253.

Dubey JP 1968. Isolation of Toxoplasma gondii from the feces of a helminth free cat. J Protozool 15: 773-775.

Dubey JP 1977. Toxoplasma, Hammondia, Besnoitia, Sarcocystis and other cyst forming coccidian of humans and animals. In JP Kreier, Parasitic Protozoa, 1st ed., vol 3, Academic Press, New York, p. 101-273.

Dubey JP 1997a. Bradyzoite induced murine toxoplasmosis: stage conversion, pathogenisis and tissue cyst formation in mice fed bradyzoites of different strains of Toxoplasma gondii. J Eukaryot Microbiol 44: 592-602.

Dubey JP 1997b.Tissue cyst tropism in Toxoplasma gondii: a comparison of tissue cyst formation in organs of cats and rodents fed oocysts. Parasitology 115: 15-20.

Dubey JP, Lindsey DS, Speer CA 1998. Structure of Toxoplasma gondii tachyzoites, bradyzoites and sporozoites and biology and development of tissue cysts. Clin Microbiol Rev 11: 267-299.

Dubey JP, Miller NL, Frenkel JK 1970. The Toxoplasma gondii oocyst from cat feces. J Exp Med 132: 636-662.

Dubey JP, Speer CA, Shen SK, Kwon OCH, Blixt JA 1997. Oocyst-induced murine toxoplasmosis: lefe cycle, pathogenicity, and stage conversion in mice fed Toxoplasma gondii oocysts. J Parasitol 82: 870-872.

Dubremetz JF 2007. Rhoptries are major players in Toxoplasma gondii invasion and host cell interaction. Cell Microbiol 9: 841-848.

Dubremetz JF 2008. Ins and outs of protein traffic in Apicomplexa. Traffic 9: 625-626.

Feldman HA 1953. The clinical manifestations and laboratory diagnosis of toxoplasmosis. Am J Trop Med Hyg 2: 420-428.

Ferguson DJ 2002. Toxoplasma gondii and sex: essential or optional extra? Trends Parasitol 18: 355-359.

Ferguson DJ 2004. Use of molecular and ultrastructural markers to evaluate stage conversion of Toxoplasma gondii in both the intermediate and definitive host. Int J Parasitol 34: 347-360.

Ferguson DJ, Brecht S, Soldati D 2000. The microneme protein MIC4 or an MIC4-like protein is expressed within the macrogamete and associated with oocyst wall formation in Toxoplasma gondii. Int $J$ Parasitol 30: 1203-1209. 
Ferguson DJP, Campell SA, Henriquez FL, Phan L, Mui E, Richards TA, Muench SP, Allary M, Lu JZ, Prigge ST, Tomley F, Shirley MW, Rice DW, McLeod R, Roberts CW 2007. Enzymes of type II fatty acid synthesis and apicoplast differentiation and division in Eimeria tenella. Inter J Parsit 37: 33-51.

Ferguson DJ, Cesbron-Delauw MF, Dubremetz JF, Sibley LD, Joiner KA, Wright S 1999. The expression and distribution of dense granule proteins in the enteric (Coccidian) forms of Toxoplasma gondii in the small intestine of the cat. Exp Parasitol 91: 203-211.

Ferguson DJ, Hutchison WM 1981. Comparison of the development of avirulent and virulent strains of Toxoplasma gondii in the peritoneal exudate of mice. Ann Trop Med Parasitol 75: 539-546.

Ferguson DPJ, Hutchison WM 1987a. The host-parasite relationship of Toxoplasma gondii in the brains of chronically infected mice. Virchows Arch A Pathol Anat Histopathol 411: 39-43.

Ferguson, DJP, Hutchison WM 1987b. An ultrastructural study of the early development and tissue cyst formation of Toxoplasma gondii in the brains of mice. Parasitol Res $73: 483-491$.

Ferguson DJP, Hutchison WM, Dunachie JF, Siim JC 1974. Ultrastructural study of early stages of asexual multiplication and microgametogony of Toxoplasma gondii in the small intestine of the cat. Acta Pathol Microbiol Scand B Microbiol Immunol 82: 167-181.

Ferguson DJP, Hutchison WM, Pettersen E 1989. Tissue cyst rupture in mice chronically infected with Toxoplasma gondii. An immunocytochemical and ultrastructural study. Parasitol Res 75: 599-603.

Ferguson DJP, Hutchison WM, Siim JC 1975. The ultrastructural development of the macrogamete and formation of the oocyst wall of Toxoplasma gondii. Acta Pathol Microbiol Scand B Microbiol Immunol 83: 491-505.

Ferguson DJP, Sahoo N, Pinches RA, Bumstead JM, Tomley FM, Gubbers MJ 2008. MORN1 has a conserved role in asexual and sexual development across the Apicomplexa. Eukaryotic Cell 7: 698-711.

Ferreira IM, Vidal JE, Costa-Silva TA, Meira CS, Hiramoto RM, Penalva de Oliveira AC, Pereira-Chioccola VL 2008. Toxoplasma gondii: genotyping of strains from Brazilian AIDS patients with cerebral toxoplasmosis by multilocus PCR-RFLP markers. Exp Parasitol 118: 22122-22127.

Fichera ME, Roos DS 1997. A plastid organelle as a drug target in apicomplexan parasites. Nature 390: 407-409.

Frenkel JK, Dubey JP, Miller NL 1969. Toxoplasma gondii: fecal forms separated from eggs of the nematode Toxocara cati. Science 164: 432-433.

Frenkel JK, Dubey JP, Miller NL 1970. Toxoplasma gondii in cats: fecal stages identified as coccidian oocysts. Science 167: 893-896.

Frenkel JK, Jacobs L 1958. Ocular toxoplasmosis. Arch Ophthal (Chicago) 48: 260-279.

Gajria B, Bahl A, Brestelli J, Dommer J, Fischer S, Gao X, Heiges M, Iodice J, Kissinger JC, Mackey AJ, Pinney DF, Roos DS, Stoeckert CJ Jr, Wang H, Brunk BP 2008. ToxoDB: an integrated Toxoplasma gondii database resource. Nucleic Acids Res 36: D553-556.

Gallino A, Maggiorini M, Kiowski W, Martin X, Wunderli W, Schneider J, Turina M, Follath F 1996. Toxoplasmosis in heart transplant recipients. Eur J Clin Microbiol Infect Dis 15: 389-393.

Goodwin DG, Strobl J, Mitchell SM, Zajac AM, Lindsay DS 2008. Evaluation of the mood-stabilizing agent valproic acid as a preventative for toxoplasmosis in mice and activity against tissue cysts in mice. J Parasitol 94: 555-557.

Gross U, Bormuth H, Gaissmaier C, Dittrich C, Krenn V, Bohne W, Ferguson DJP 1995. Monoclonal rat antibodies directed against
Toxoplasma gondii suitable for studying tachyzoite-bradyzoite interconversion in vivo. Clin Diagn Lab Immunol 2: 542-548.

Gubbels MJ, Striepen B 2004. Studying the cell biology of apicomplexan parasites using fluorescent proteins. Microsc Microanal 10: $568-579$.

Guimaraes EZ, Carvalho L, Barbosa HS 2008. Primary culture of skeletal muscle cells as a model for studies of Toxoplasma gondii cystogenesis. J Parasit 94: 72-83.

Heydorn AO, Mehlhorn H 1978. Light and electron microscopic studies on Sarcocystis suihominis.2. The schizogony preceding cyst formation. Zbl Bakt Hyg I Abt Orig A 240: 123-134.

Horowitz SL, Bentson JR, Benson F, Davos I, Pressman B, Gottlieb MS 1983. CNS toxoplasmosis in acquired immunodeficiency syndrome. Arch Neurol 40: 649-652.

Howe DK, Honoré S, Derouin F, Sibley LD 1997. Determination of genotypes of Toxoplasma gondii strains isolated from patients with toxoplasmosis. J Clin Microbiol 35: 1411-1414.

Howe DK, Sibley LD 1995. Toxoplasma gondii comprises three clonal lineages: correlation of parasite genotype with human disease. $J$ Infect Dis 172: 1561-15616.

Hutchison WM 1965. Experimental transmission of Toxoplasma gondii. Nature 206: 962-962.

Hutchison WM 1967. The nematode transmission of Toxoplasma gondii. Trans R Soc Trop Med Hyg 61: 80-89.

Hutchison WM, Dunachie JF, Siim J C, Work K 1969. The life cycle of Toxoplasma gondii. Brit Med J 4: 806.

Hutchison WM, Dunachie JF, Work K 1968. The faecal transmission of Toxoplasma gondii. Acta Pathol Microbiol Scand 74: 462-464.

Hutchison WM, Dunachie JF, Work K, Siim JC 1971. The life cycle of the coccidian parasite Toxoplasma gondii in the domestic cat. Trans R Soc Trop Med Hyg 65: 380-399.

Israelski DM, Remington JS 1988. Toxoplasmic encephalitis in patients with AIDS. Infect Dis Clin North Am 2: 429-445.

Jacobs L 1963. Toxoplasma and toxoplasmosis. Ann Rev Microbiol 17: 429-450.

Jacobs L 1967. Toxoplasma and toxoplasmosis. Adv Parasitol 5 :1-45.

Jacobs L, Remingtin JS, Melton ML 1960. The resistance of the encysted form of Toxoplasma gondii. J Parasitol 46: 11-21.

Joiner KA, Roos DS 2002. Secretory traffic in the eukaryotic parasite Toxoplasma gondii: less is more. J Cell Biol 157: 557-563.

Jones-Brando L, Torrey EF, Yolken R 2003. Drugs used in the treatment of schizophrenia and bipolar disorder inhibit the replication of Toxoplasma gondii. Schizophr Res 62: 237-244.

Khan A, Böhme U, Kelly KA, Adlem E, Brooks K, Simmonds M, Mungall K, Quail MA, Arrowsmith C, Chillingworth T, Churcher C, Harris D, Collins M, Fosker N, Fraser A, Hance Z, Jagels K, Moule S, Murphy L, O'Neil S, Rajandream MA, Saunders D, Seeger K, Whitehead S, Mayr T, Xuan X, Watanabe J, Suzuki Y, Wakaguri H, Sugano S, Sugimoto C, Paulsen I, Mackey AJ, Roos DS, Hall N, Berriman M, Barrell B, Sibley LD, Ajioka JW 2006a. Common inheritance of chromosome Ia associated with clonal expansion of Toxoplasma gondii. Genome Res 16: 1119-1125.

Khan A, Fux B, Su C, Dubey JP, Darde ML, Ajioka JW, Rosenthal BM, Sibley LD 2007. Recent transcontinental sweep of Toxoplasma gondii driven by a single monomorphic chromosome. Proc Natl Acad Sci USA 104: 14872-14877.

Khan A, Jordan C, Muccioli C, Vallochi AL, Rizzo LV, Belfort R Jr, Vitor RW, Silveira C, Sibley LD 2006b. Genetic divergence of 
Toxoplasma gondii strains associated with ocular toxoplasmosis, Brazil. Emerg Infect Dis 12: 942-949.

Khan A, Taylor S, Su C, Mackey AJ, Boyle J, Cole R, Glover D, Tang K, Paulsen IT, Berriman M, Boothroyd JC, Pfefferkorn ER, Dubey JP, Ajioka JW, Roos DS, Wootton JC, Sibley LD 2005. Composite genome map and recombination parameters derived from three archetypal lineages of Toxoplasma gondii. Nucleic Acids Res 33: 2980-2992.

Kim K, Soldati Dand Boothroyd JC 1993. Gene replacement in Toxoplasma gondii with chloramphenicol acetyltransferase as selectable marker. Science 262: 911-914.

Köhler S, Delwiche CF, Denny PW, Tilney LG, Webster P, Wilson RJ, Palmer JD, Roos DS 1997. A plastid of probable green algal origin in Apicomplexan parasites. Science 275: 1485-1489.

Lainson R 1958. Observations on the development and nature of pseudocysts and cysts of Toxoplasma gondii. Trans $R$ Soc Trop Med Hyg 52: 396-407.

Lehmann T, Marcet PL, Graham DH, Dahl ER, Dubey JP 2006. Globalization and the population structure of Toxoplasma gondii. PNAS 103: 11423-11428.

Levine ND, Corliss JO, Cox FE, Deroux G, Grain J, Honigberg BM, Leedale GF, Loeblich AR 3rd, Lom J, Lynn D, Merinfeld EG, Page FC, Poljansky G, Sprague V, Vavra J, Wallace FG 1980. A newly revised classification of the protozoa. J Protozool 27: 37-58.

Luft BJ, Brooks RG, Conley FK, McCabe RE, Remington JS 1984 Toxoplasmic encephalitis in patients with acquired immune deficiency syndrome. JAMA 252: 913-917.

McFadden GI, Reith ME, Munholland J, Lang-Unnasch N 1996. Plastid in human parasites. Nature 381: 482.

Mercier C, Adjogble KD, Däubener W, Delauw MF 2005. Dense granules: are they key organelles to help understand the parasitophorous vacuole of all apicomplexa parasites? Int J Parasitol 35: 1611-1612.

Morisset S, Peyron F, Lobry JR, Garweg J, Ferrandiz J, Musset K, Gomez-Marin JE, de la Torre A, Demar M, Carme B, Mercier C, Garin JF, Cesbron-Delauw MF 2008. Serotyping of Toxoplasma gondii: striking homogeneous pattern between symptomatic and asymptomatic infections within Europe and South America. Microbes Infect 10: 742-747.

Navia BA, Petito CK, Gold JW, Cho ES, Jordan BD, Price RW 1986. Cerebral toxoplasmosis complicating the acquired immune deficiency syndrome: clinical and neuropathological findings in 27 patients. Ann Neurol 19: 224-238.

Nicolle C, Manceaux L 1908. Sur une infection a corps de Leishman (ou organismes voisons) du gondi. C R Acad Sci 147: 736.

Nicolle C, Manceaux L 1909. Sur un protozoaire nouveau du gondi. C R Acad Sci 148: 369.

Overdulve JP 1970. The identity of Toxoplasma Nicolle \& Manceaux, 1909 with Isospora Schneider, 1881 (I). Konink Nederl Akad van Wetenschappen (Amsterdam) Proceedings 73 (Series C): 129-151.

Peyron F, Lobry JR, Musset K, Ferrandiz J, Gomez-Marin JE, Petersen E, Meroni V, Rausher B, Mercier C, Picot S, Cesbron-Delauw MF 2006. Serotyping of Toxoplasma gondii in chronically infected pregnant women: predominance of Type II in Europe and Types I and III in Colombia (South America). Microbes Infect 8: 2333-2340.

Pfefferkorn ER, Pfefferkorn LC 1977. Toxoplasma gondii: characterization of a mutant resistant to 5-fluorodeoxyuridine. Exp Parasitol 42: 44-55.

Pfefferkorn ER, Pfefferkorn LC 1979. Quantitative studies of the mutagenesis of Toxoplasma gondii. J Parasitol 65: 364-370.
Pfefferkorn ER, Pfefferkorn LC, Colby ED 1977. Development of gametes and oocysts in cats fed cysts derived from cloned trophozoites of Toxoplasma gondii. J Parasitol 63: 158-159.

Pfefferkorn LC, Pfefferkorn ER 1980. Toxoplasma gondii: genetic recombination between drug resistant mutants. Exp Parasitol 50: 305-316.

Pinkerton H, Weinman D 1940. Toxoplasma infection in man. Arch Pathol 30: 374-392.

Roos DS, Donald RG, Morrissette NS, Moulton ALC 1994. Molecular tools for genetic dissection of the protozoan parasite Toxoplasma gondii. Methods Cell Biol 45: 28-61.

Ruskin J, Remington JS 1976. Toxoplasmosis in the compromised host. Ann Intern Med 84: 193-199.

Sabin AB 1942. Toxoplasmosis, a recently recognized disease of human beings. Advances Pediat 1: 1-60.

Sabin AB, Feldman HA 1948. Dyes as microchemical indicators of a new immunity phenomenon affecting a protozoon parasite (Toxoplasma). Science 108: 660-663.

Sabin AB, Olitsky PK 1937. Toxoplasma and obligate intracellular parasitism. Science 85: 336-338.

Saeij JP, Boyle JP, Boothroyd JC 2005. Differences among the three major strains of Toxoplasma gondii and their specific interactions with the infected host. Trends Parasitol 21: 476-481.

Scholtyseck E, Mehlhorn H 1970. Ultrastructural study of characteristic organelles (paired organelles, micronemes, micropores) of sporozoa and related organisms. Z Parasitenkd 34: 97-127.

Scholtyseck E, Mehlhorn H, Hammond DM 1972. Electron microscope studies of microgametogenesis in Coccidia and related groups. Z Parasitenkd 38: 95-131.

Sheffield HG, Melton ML 1968. The fine structure and reproduction of Toxoplasma gondii. J Parasitol 54: 209-226.

Sheffield HG, Melton ML 1969. Toxoplasma gondii: transmission through feces in the absence of Toxocara cati eggs. Science 164: 431-432.

Sheffield HG, Melton ML 1970. Toxoplasma gondii: the oocyst, sporozoite and infection of cultured cells. Science 167: 892-893.

Sibley LD, LeBlanc AJ, Pfefferkorn ER, Boothroyd JC 1992. Generation of a restriction fragment length polymorphism linkage map for Toxoplasma gondii. Genetics 132: 1003-1015.

Sibley LD, Messina M, Niesman IR 1994. Stable DNA transformation in the obligate intracellular parasite Toxoplasma gondii by complementation of tryptophan auxotroph. Proc Natl Acad Sci USA 91: 5508-5512.

Siim JC 1955. Aetiological investigations in acquired toxoplasmosis with lymphadenopathy in children and adults. Proc R Soc Med 48: 1067-1071.

Soldati D, Boothroyd JC 1993. Transient transfection and expression in the obligate intracellular parasite Toxoplasma gondii. Science 260: 349-352.

Soldati D, Kim K, Kampmeier J, Dubremetz JF, Boothroyd JC 1995. Complementation of a Toxoplasma gondii ROP1 knock-out mutant using phleomycin selection. Mol Biochem Parasitol 74: 87-97.

Speer CA, Dubey JP 1981. An ultrstructural study of first and secondgeneration merogony in the coccidian Sarcocyst tenella. J Protozool 28: 434-431.

Speer CA, Dubey JP 2005. Ultrastructural differentiation of Toxoplasma gondii schizonts (types B to E) and gamonts in the intestines of cats fed bradyzoites. Int J Parasitol 35: 193-206. 
Splendore A 1908. Un nuovo protozoa parassita deconigli incontrato nelle lesioni anatomiche d'une malattia che ricorda in molti punti il Kala-azar dell'uoma. Nota preliminare pel. Rev Soc Sci Sao Paulo 3: 109-112.

Striepen B, He CY, Matrajt M, Soldati D, Roos DS 1998. Expression, selection and organellar targeting of the green fluorescent protein in Toxoplasma gondii. Mol Biochem Parasitol 92: 325-338.

Striepen B, Jordan CN, Reiff S, van Dooren GG 2007. Building the perfect parasite: cell division in apicomplexa. PLoS Pathog 3: e78.

Striepen B, Soldati D, Garcia-Reguet N, Dubremetz JF, Roos DS 2001. Targeting of soluble proteins to the rhoptries and micronemes in Toxoplasma gondii. Mol Biochem Parasitol 113: 45-53.

Su C, Evans D, Cole RH, Kissinger JC, Ajioka JW, Sibley LD 2003. Recent expansion of Toxoplasma through enhanced oral transmission. Science 299: 414-416.

Tenter AM, Heckeroth AR, Weiss LM 2000. Toxoplasma gondii: from animals to humans. Int J Parasitol 30: 1217-1258.

Torrey EF, Bartko JJ, Lun ZR, Yolken RH 2007. Antibodies to Toxoplasma gondii in patients with schizophrenia: a meta-analysis. Schizophr Bull 33: 729-736.

Torrey EF, Yolken RH 2007. Schizophrenia and toxoplasmosis. Schizophr Bull 33: 727-728.

Vallochi AL, Muccioli C, Martins MC, Silveira C, Belfort R Jr, Rizzo LV 2005. The genotype of Toxoplasma gondii strains causing ocular toxoplasmosis in humans in Brazil. Am J Ophthalmol 139: 350-351.

Velimirovic B 1984. Toxoplasmosis in immunosuppression and AIDS. Infection 12: 315-317.

Vivier E 1970. Observations nouvelles sur la reproduction asexuee de Toxoplasma gondii et considerations sur la notion d'rndogenese. C R Acad Sci Paris 27: 2123-2126.

Vyas A, Kim SK, Giacomini N, Boothroyd JC, Sapolsky RM 2007. Behavioral changes induced by Toxoplasma infection of rodents are highly specific to aversion of cat odors. Proc Natl Acad Sci USA 104: 6442-6447.

Webster JP 2007. The effect of Toxoplasma gondii on animal behaviour: playing cat and mouse. Schizophr Bull 33: 752-756.

Webster JP, Lamberton PH, Donnelly CA, Torrey EF 2006. Parasites as causative agents of human affective disorders? The impact of anti-psychotic, mood-stabilizer and anti-parasite medication on Toxoplasma gondii's ability to alter host behaviour. Proc Biol Sci 273: $1023-1030$.

Weinman D, Chandler AH 1954. Toxoplasmosis in swine and rodents. Reciprocal oral infection and potential human hazard. Proc Soc Exp Biol Med 87: 211-216.

Weiss LM, Kim K 2007. Toxoplasma gondii the modal apicomplexan: perspectives and methods. Academic Press, London, 777 pp.

Wilder HC 1952. Toxoplasma chorioretinitis in adults. Arch Opthal (Chicago) 48: 127-137.

Wilson RJ, Denny PW, Preiser PR, Rangachari K, Roberts K, Roy A, Whyte A, Strath M, Moore DJ, Moore PW, Williamson DH 1996. Complete gene map of the plastid-like DNA of the malaria parasite Plasmodium falciparum. J Mol Biol 261: 155-172.

Witte HM, Piekarski G 1970. Die Oocysten-Ausscheidung bei experimentall infizierten Katzen in Abhangigkeit von ToxoplasmaStamm. Z Parasitenk 33: 358-360.

Wolf A, Cowen D 1937. Granulomatous encephalomyelitis due to an encephalitozoon (encephalitozic ancephalomyelitis): a new protozoan disease of man. Bull Neurol Inst NY 6: 306-335.

Wolf A, Cowen D, Paige B 1939. Human toxoplasmosis: occurrence in infants as an encephalomyelitis verification by transmission to animals. Science 89: 226-227.

Wolf A, Cowen D, Paige BH 1940. Toxplasmic encephalomyelitis. IV. Experimental transmission of the infection to animals from a human infant. $J$ Exp Med 71: 187-214.

Wolf A, Cowen D, Paige BH 1941. Fetal encephalomyelitis: prenatal inception of infantile toxoplasmosis. Science 93: 548-549.

Work K, Hutchison WH 1969. A new cyst of Toxoplasma gondii. Acta Path Microbiol Scand 77: 414-424.

Xia D, Sanderson SJ, Jones AR, Prieto JH, Yates JR 3rd, Bromley E, Tomley FM, Lal K, Sinden RE, Brunk BP, Roos DS, Wastling JM 2008. The proteome of Toxoplasma gondii: integration with the genome provides novel insights into gene expression and annotation. Genome Biol 9: R116.

Zhou XW, Kafsack BF, Cole RN, Beckett P, Shen RF, Carruthers VB 2005. The opportunistic pathogen Toxoplasma gondii deploys a diverse legion of invasion and survival proteins. J Biol Chem 280: 34233-34244. 